\title{
The Age of Reason: Financial Decisions over the Life Cycle and Implications for Regulation
}

\begin{abstract}
Many consumers make poor financial choices, and older adults are particularly vulnerable to such errors. About half of the population between ages 80 and 89 have a medical diagnosis of substantial cognitive impairment. We study life-cycle patterns in financial mistakes using a proprietary database with information on 10 types of credit transactions. Financial mistakes include suboptimal use of credit card balance transfer offers and excess interest rate and fee payments. In a cross section of prime borrowers, middle-aged adults made fewer financial mistakes than either younger or older adults. We conclude that financial mistakes follow a U-shaped pattern, with the cost-minimizing performance occurring around age 53. We analyze nine regulatory strategies that may help individuals avoid financial mistakes. We discuss laissez-faire, disclosure, nudges, financial "driver's licenses," advance directives, fiduciaries, asset safe harbors, and ex post and ex ante regulatory oversight. Finally, we pose seven questions for future research on cognitive limitations and associated policy responses.
\end{abstract}

ost households in the United States have accumulated a substantial pool of wealth by the time they retire. Among households with a head aged 65-74, median net worth-including net home equity but excluding public and private defined-benefit claims-was $\$ 239,400$ in 2007, according to the 2007 Survey of Consumer Finances (SCF). ${ }^{1}$ Moreover, household

1. For this group of households, mean net worth, again excluding defined-benefit accounts, was $\$ 1,015,700$ in 2007 . However, the mean is dominated by the right tail of the distribution, and saving for these households is motivated by many considerations other than retirement (particularly the desire to make bequests and the need for capital in ongoing privately held businesses). 
wealth is likely to grow much more quickly than income in the next three decades, as more and more households experience a full career's worth of accumulation in defined-contribution pension accounts such as $401(\mathrm{k}) \mathrm{s}^{2}{ }^{2}$

In addition to their accumulated assets, households with a head aged 65-74 often have a complex set of balance sheet liabilities: the SCF reports that in 2007, 47.9 percent had debt secured by a residential property, 26.1 percent had installment loans, and 37 percent carried credit card balances from month to month. Nearly two-thirds ( 65.5 percent) of households in this age range had at least one form of debt.

In this paper we seek to raise a red flag about the increasingly large and complex balance sheets of older adults. Substantial retirement savings are critical for the well-being of this group in light of the increasing average length of retirement, the rising expectation of independent living through most of retirement, and more modest defined-benefit flows for most retirees. However, many older adults are not in a good position to manage their finances, or even to delegate that management safely to others. We document this concern in four ways.

First, we review the literature on age-based patterns in cognitive function. Performance on novel cognitive tasks-what psychologists call fluid intelligence-declines dramatically over one's adult life. In the cross section, the fluid intelligence of the average individual falls by about 1 percentile unit each year from age 20 to age 80 (Salthouse forthcoming and authors' calculations). Many mechanisms contribute to explaining this pattern, including (confounding) cohort effects, normal aging effects, and dementia. The prevalence of dementia explodes after age 60, doubling with every five years of age to more than 30 percent after age 85 (Ferri and others 2005). Moreover, many older adults without a strict diagnosis of dementia still experience substantial cognitive impairment. For example, the prevalence of the diagnosis "cognitive impairment without dementia" is nearly 30 percent between ages 80 and 89. ${ }^{3}$ Drawing these facts together, about half the population aged $80-89$ have a diagnosis of either dementia or cognitive impairment without dementia.

Second, we supplement these existing findings with new longitudinal evidence from the University of Michigan's Health and Retirement Study (HRS). Our new evidence eliminates the confound of cohort effects by

2. Poterba, Venti, and Wise (2008). Today fewer than half of the private sector workforce have a defined-contribution plan at their current employer. However, current legislative proposals are likely to expand coverage.

3. Plassman and others (2008). They define cognitive impairment without dementia as a Dementia Severity Rating Scale score between 6 and 11. 
estimating age effects that control for person fixed effects. When we do this, we find even stronger age-based patterns. Our results imply that age-based selection effects are very strong - the most impaired subjects tend to drop out of these surveys-explaining why cross-sectional patterns of cognitive decline understate the true age-based decline.

Third, using a new dataset, we document a link between age and the quality of financial decisionmaking in debt markets. In a cross section of prime borrowers, middle-aged adults borrow at lower interest rates and pay less in fees than do either younger or older adults. Averaging results across 10 different types of credit transactions, we find that fee and interest payments are minimized around age 53. These measured effects are not explained by differences in observed risk characteristics. Combining multiple datasets, neither do we find evidence that selection effects or cohort effects explain our results. The leading explanation for the patterns that we observe is that experience and acquired knowledge rise with age, but fluid intelligence declines with it.

Fourth, we review the contributions of other authors who have studied age effects on financial decisionmaking. A small but rapidly growing body of convergent research highlights the cognitive vulnerabilities of older adults. Questions remain about the identification of age, cohort, and time effects. Moreover, even if we were certain that older adults make many suboptimal financial decisions, it is not clear what society should do about it.

We next present a discussion of mutually compatible policy options for addressing the identified problems. Although some of our field evidence suggests that younger adults are also at risk, our regulatory analysis emphasizes older adults, for four reasons. First, older adults have much more at stake, since they control far more financial resources, both absolutely and as a fraction of their total net worth, than people in their 20s. Second, older adults cannot as easily bounce back from their financial mistakes, since their cognitive and physical disabilities frequently make it difficult to return to work. Third, younger adults may make frequent financial mistakes, but they rarely have severe cognitive incapacity. The behavior of a foolish 20 -year-old credit card user bears little comparison to that of an 80-yearold suffering from dementia. For example, one regularly hears stories about friends' aging relatives who lend or give a substantial fraction of their wealth to con artists (see, for example, Choi-Allum 2009). Fourth, in the United States at least, retirees effectively have fewer regulatory protections than do most workers. This is an unintended consequence of the nation's system of defined-contribution retirement savings. Definedcontribution pension accounts are stringently regulated by the Employee 
Retirement Income Security Act (ERISA). ${ }^{4}$ However, almost all retirees eventually roll their accumulated balances out of ERISA-regulated accounts into Individual Retirement Accounts (IRAs), which are regulated with a much lighter touch. For example, the broker-dealer securities firms that manage most IRAs have no fiduciary duty toward their customers. Thus, the system currently provides the least regulation for precisely the age group with the greatest vulnerability.

We identify and discuss nine policy options, listed here in approximate order from least to most paternalistic:

-Laissez-faire

- Increased disclosure

— "Libertarian paternalism" (the greater use of advice, defaults, and other nudges)

-Financial "driver's licenses"

-Advance directives (instructions set out today against a future loss of competence)

-Expanded fiduciary requirements

-Protection of assets through sequestration in known safe investments ("safe harbors")

-Default regulatory approval of financial products, with ex post sanctions for violation of standards

- Mandatory ex ante regulatory review of financial products. We discuss the pros and cons of each of these different regulatory models, without arguing for the adoption of any one of them. We believe that natural experiments are needed to determine their efficacy, and we recognize that the stronger interventions have the potential to generate large social costs as well as benefits.

Finally, we identify seven critical research questions that need to be answered before policymakers can identify an optimal regulatory design. These questions highlight how little is currently known about the financial choices of older adults.

The paper is organized as follows. Section I discusses medical and psychological evidence on changes in cognitive function over the life cycle. Section II discusses evidence from the HRS on age-based changes in

4. ERISA requires plans to provide participants with information about the plan, including important information about plan features and funding; establishes fiduciary responsibilities for those who manage and control plan assets; requires plans to establish a grievance and appeals process for participants; and gives participants the right to sue for benefits and over breaches of fiduciary duty. (See the U.S. Department of Labor's webpage on ERISA at www.dol.gov/dol/topic/health-plans/erisa.htm.) 
cognitive function, controlling for person fixed effects. Section III discusses the evidence on errors made by older adults in debt markets. Section IV discusses the broader literature on economic decisionmaking over the life cycle. Section V analyzes the nine policy approaches listed above. Section VI concludes by posing our seven questions for future research.

\section{Psychological and Medical Evidence on Cognitive Decline among Older Adults}

Fluid intelligence (performance on novel tasks) can be measured along many different dimensions, including working memory, reasoning, spatial visualization, and cognitive processing speed. Figure 1, from a forthcoming paper by Timothy Salthouse, illustrates each of these kinds of tasks.

Fluid intelligence shows a robust age pattern in cross-sectional datasets of adults (Cattell 1987; Salthouse 2005; Salthouse forthcoming). Adults in their early 20 s score on average about 0.7 standard deviation above the adult mean, and adults in their early 80 s about 1.0 standard deviation below

Figure 1. Examples of Memory and Analytical Tests

\section{Memory}

Study the following words and then write as many as you can remember
Goat
Door
Fish
Desk
Rope
Lake
Boot
Frog
Soup
Mule

\section{Spatial Visualization}

Select the object on the right that corresponds to the pattern on the left

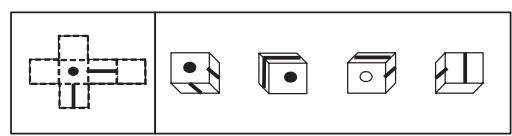

\section{Reasoning}

Select the best completion of the missing cell in the matrix
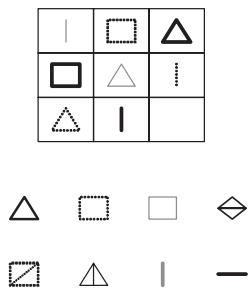

\section{Perceptual Speed}

Classify the pairs as same (S) or different (D) as quickly as possible

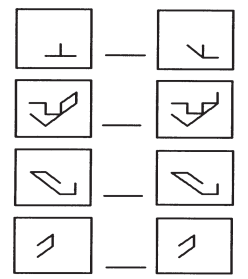

Source: Salthouse (forthcoming). Reprinted with permission. 
Figure 2. Performance on Memory and Analytical Tasks by Age

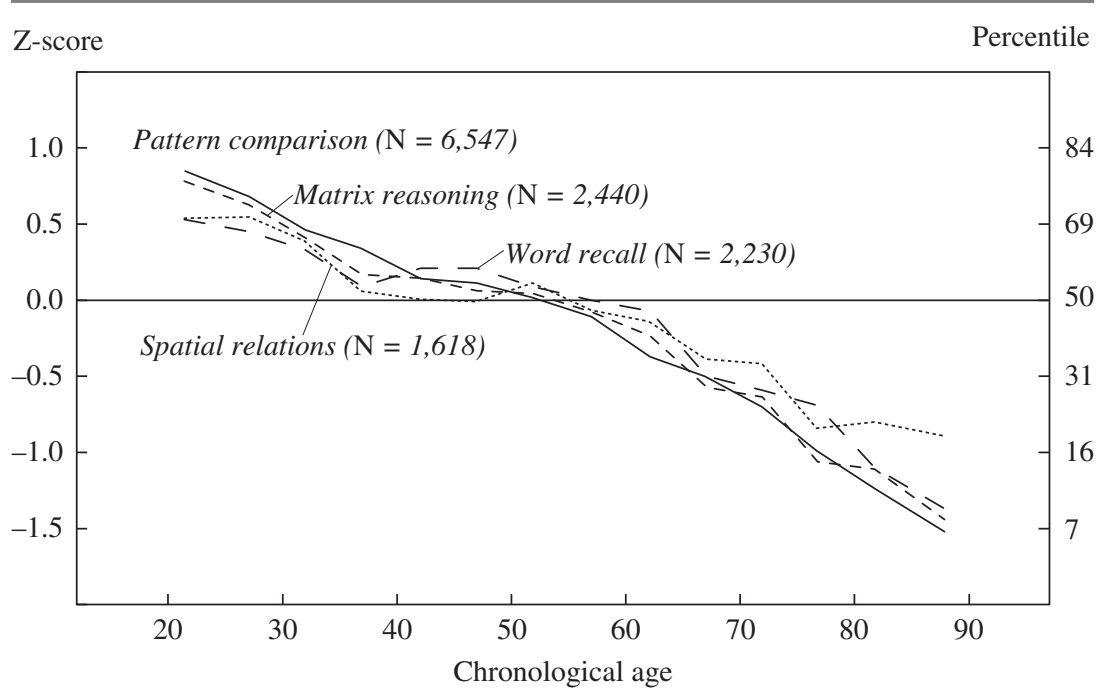

Source: Salthouse (forthcoming). Reprinted with permission.

the mean. This implies a decline of about 1 percentile of the total adult population per year after age 20, assuming the distribution is Gaussian. Indeed, this decline is remarkably smooth from age 20 to age 90 (figure 2). The measured pattern results from some combination of true age effects, cohort effects (Flynn 1984), and selection effects. We return to the issue of identification of age effects in the next section, where we report new evidence from the HRS.

Neurological pathologies represent one important pathway for age effects on performance in older adults. For instance, dementia is primarily attributable to Alzheimer's disease (in about 60 percent of cases) and vascular disease (in about 25 percent). The prevalence of dementia doubles with every five additional years of life (Ferri and others 2005; Fratiglioni, De Ronchi, and Agüero-Torres 1999). ${ }^{5}$ For example, the top panel of table 1 reports that the prevalence of dementia in North America rises from 3.3 percent at ages 70-74 to 6.5 percent at ages $75-79,12.8$ percent at ages $80-84$, and 30.1 percent for adults at least 85 years of age (Ferri and others 2005).

5. There is also a growing literature that identifies age-related changes in the nature as opposed to the quality of cognition (see Park and Schwarz 2000; Denburg, Tranel, and Bechara 2005). Mather and Carstensen (2005) and Carstensen (2006) identify age-related variation in cognitive preferences. Subjects with short time horizons and older subjects attend to negative information relatively less than do subjects with long time horizons or younger subjects. 
Table 1. Prevalence of Cognitive Impairment by Age in North America Percent

\begin{tabular}{lcc}
\hline Age & Prevalence & 95 percent confidence interval \\
\hline Dementia & & \\
$60-64$ & 0.8 & $0.6-1.0$ \\
$65-69$ & 1.7 & $1.5-1.9$ \\
$70-74$ & 3.3 & $2.7-3.9$ \\
$75-79$ & 6.5 & $5.5-7.5$ \\
$80-84$ & 12.8 & $11.8-13.8$ \\
85 and over & 30.1 & $27.9-32.3$ \\
Cognitive impairment without dementia & \\
$71-79$ & 16.0 & $11.5-20.5$ \\
80-89 & 29.2 & $24.3-34.1$ \\
90 and over & 38.8 & $25.6-52.0$ \\
All ages & 22.0 & $18.5-22.5$ \\
\hline
\end{tabular}

Sources: Ferri and others (2005); erratum to Plassman and others (2008).

Many older adults suffer from a less severe form of cognitive impairment, which is diagnosed as cognitive impairment without dementia. The prevalence of this diagnosis rises from 16.0 percent at ages 71-79 to 29.2 percent at ages 80-89 (bottom panel of table 1). All told, about half of adults in their 80s suffer from either dementia or cognitive impairment without dementia.

Age-driven declines in fluid intelligence, however, are partly offset by age-related increases in crystallized intelligence (sometimes called experience or knowledge). ${ }^{6}$ Most day-to-day tasks, such as buying the right amount of milk at the grocery store, rely on both fluid and crystallized intelligence. For most tasks we hypothesize that net performance is humpshaped with respect to age. Formally, this would result from the following conditions: general task performance is determined by the sum of fluid and crystallized capital, crystallized capital accumulates with diminishing returns (for $m<n$, the $n$th learning experience generates less crystallized capital than the $m$ th), and fluid capital falls linearly (or perhaps concavely) over the life cycle (figure 3). Consequently, middle-aged adults may be at a decisionmaking sweet spot: they have substantial practical experience and have not yet suffered significant declines in fluid intelligence. Supporting this

6. Experience may be acquired directly, or it may be acquired indirectly through communication with peers. As people build up their social networks over their lifetime, their external sources of experience become better and better developed. However, these networks tend to fray as individuals retire and leave well-developed work-based relationships. Peer mortality also contributes to a late-life decline of social networks. These channels suggest that the experiential knowledge derived from social networks follows a concave life-cycle pattern. 
Figure 3. Relationship of Net Cognitive Performance to Crystallized and Fluid Capital

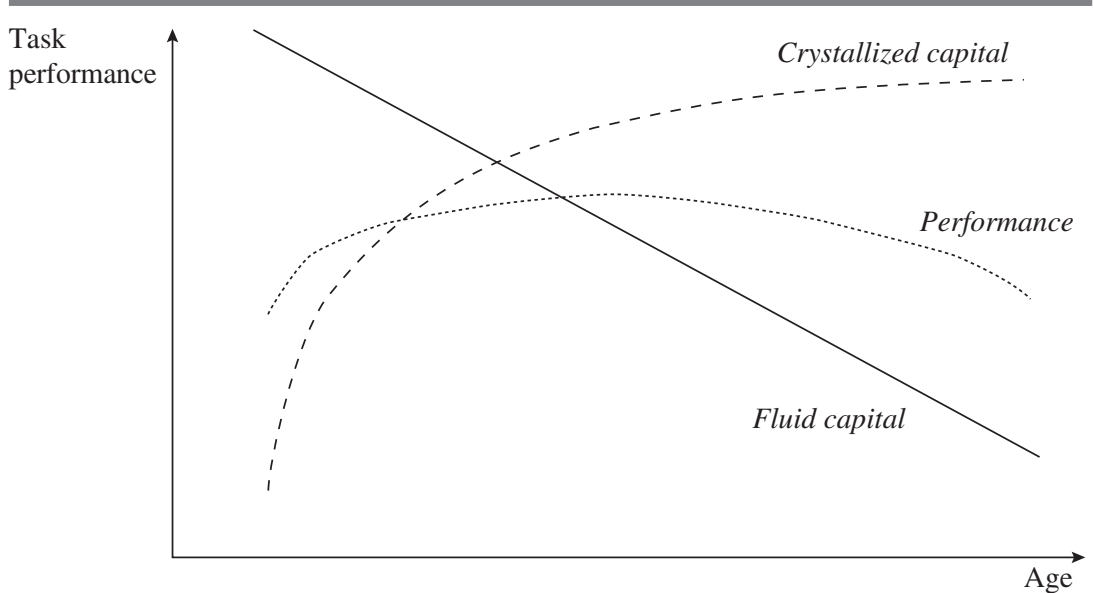

hypothesis is the fact that results of experience-based cognitive tests-for example, those testing vocabulary and other types of acquired knowledgefollow a hump-shaped pattern (Salthouse 2005).

\section{Evidence from the HRS}

The medical and psychological evidence on age-based patterns in cognitive function reviewed in the previous section is confounded by cohort effects and selection effects. In any cross section of subjects, the older subjects not only are older but also were born in different cohorts from the others. Moreover, these patterns are affected by different selection mechanisms. For example, older adults have relatively more health problems (both physical and cognitive) that cause them to selectively drop out of surveys.

\section{II.A. Evidence from the Main HRS Sample}

In light of these problems, it is useful to analyze data that follow individuals longitudinally. The HRS is an excellent source for such analysis for cognitive variables (Ofstedal, Fisher, and Herzog 2005; McArdle, Smith, and Willis forthcoming). Since its beginning in 1992, the HRS has surveyed a nationally representative sample of more than 22,000 Americans over the age of 50. These longitudinal surveys are conducted every two years. For reasons of data comparability, we use all of the waves from 1993 to 2006 . $^{7}$

7. See Ofstedal and others (2005) for a complete description of the cognitive scales in the HRS. 
Our analysis proceeds in two parallel ways. First, we undertake a "naive" analysis (mirroring the methods described in the previous section) that simply plots mean performance by age (in integer years), ignoring the potential role of cohort and selection effects. Second, we conduct a "controlled" analysis that traces out the performance trajectory using only intra-individual differences. To do this, we calculate the slope at age $a$ as the average slope for all subjects who are observed in adjacent survey waves straddling age $a{ }^{8}$ In other words, the slope at integer age $a$ is calculated as

$$
\frac{1}{N_{\Omega(a)}} \sum_{i \in \Omega(a)} \frac{x_{i, w+1}-x_{i, w}}{A_{i, w+1}-A_{i, w}}
$$

where $x_{i, w}$ is the task performance of subject $i$ in HRS wave $w, A_{i, w}$ is the decimal age of subject $i$ in wave $w, \Omega(a)$ is the set of subjects who appear in adjacent waves at ages straddling age $a$, and $N$ is the cardinality of $\Omega$. Note that this average slope implicitly controls for person fixed effects, since the slope is calculated by averaging individual slopes.

We then trace out the life-cycle trajectory using these average slopes, starting from the value of the naive analysis at an initial age. To reduce sampling noise, the initial age is chosen as the first age for which we have at least 1,000 observations in our combined sample (including all of the HRS waves from 1992 to 2006).

The top left panel of figure 4 plots naive and controlled performance in the immediate word recall task. The interviewer reads a list of 10 simple nouns, and the respondent is immediately asked to recall as many of them as possible, in any order. At age 51 the average performance is 6.2 words out of 10 . By age 90 the average (controlled) performance is 3.0 words out of 10 .

The top right panel of figure 4 plots naive and controlled performance in the delayed word recall task. This is the same as the previous task except that a second task taking about five minutes intervenes between recitation and recall. At age 51 the average performance is 5.4 words out of 10 . By age 90 the average (controlled) performance is 2.1 words out of 10 .

The middle left panel of figure 4 plots naive and controlled performance in the serial sevens task, in which the respondent is asked to count

8. In our notation, responses at dates $t$ and $t^{\prime}$ are adjacent if $\left|t^{\prime}-t\right|<5$ years and the respondent does not answer the same question at another date $t^{\prime \prime}$ between $t$ and $t^{\prime}$. For example, if a specific question was not included in the 2004 wave but was included in the 2002 and 2006 waves (and the respondent answered the question in both those waves), then the adjacent responses would be in 2002 and 2006. Two decimal ages $A<A^{\prime}$ straddle integer age $a$ iff $A<a<A^{\prime}$. 
Figure 4. Performance by Age on Six Tasks in the Health and Retirement Studya
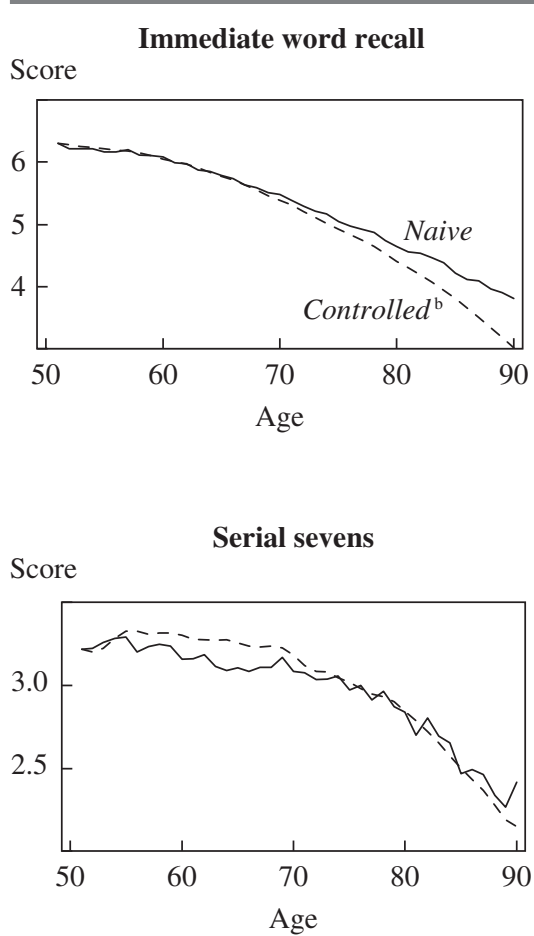

Chance of disease question

Percent giving

correct answer

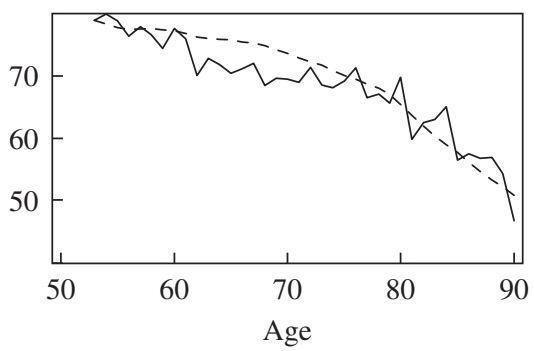

Score Delayed word recall

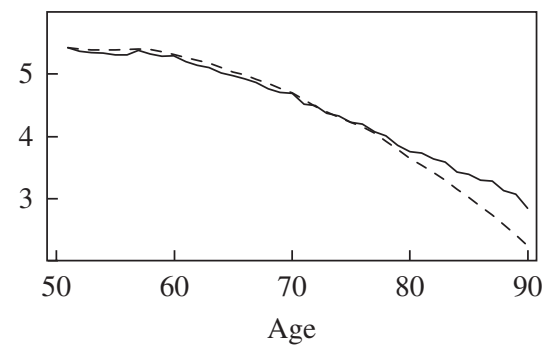

Telephone Interview of Cognitive Status

Score

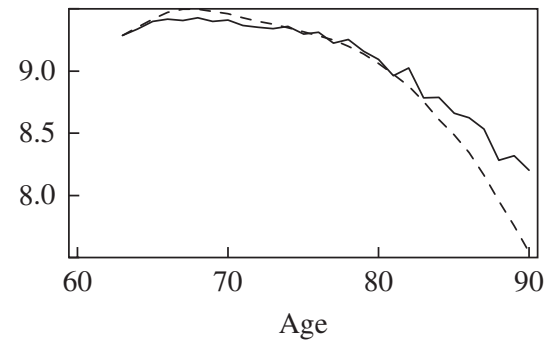

Split lottery question

Percent giving

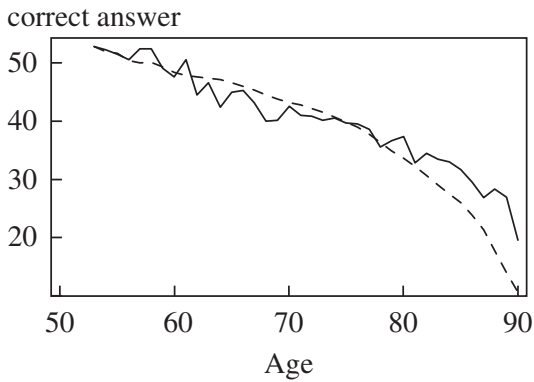

Sources: HRS data and authorsícalc ulations.

a. See the text for descriptions of the tasks.

b. Controlling for cohort and selection effects. 
backward by 7 from 100. The respondent is scored on a 1-to-5 scale, with 1 point awarded for each successful subtraction. At age 51 the average score is 3.2 out of 5. By age 90 the average (controlled) score is 2.2 out of 5 .

The middle right panel of figure 4 plots naive and controlled performance in the Telephone Interview of Cognitive Status (TICS) task. The researcher asks the respondent the following 10 questions and assigns 1 point for each correct answer: What is the current year? What is the current month? What is the current day of the month? What is the current day of the week? What do you usually use to cut paper? What do you call the kind of prickly plant that grows in the desert? Who is the current president? Who is the current vice president? Count backward from 20 to 10 (twice). At age 63 the average score is 9.2 out of 10 . By age 90 the average (controlled) score is 7.5.

Finally, we present two measures of practical numeracy. The bottom left panel of figure 4 plots naive and controlled performance in response to the following question: If the chance of getting a disease is 10 percent, how many people out of 1,000 would be expected to get the disease? At age 53, 79 percent of subjects answer correctly. By age 90, 50 percent answer correctly.

The bottom right panel of figure 4 plots naive and controlled performance in response to the following question: If five people all have the winning numbers in the lottery and the prize is $\$ 2$ million, how much will each of them get? We believe that this question is imprecisely posed, since the logical answer could be either $\$ 2$ million or $\$ 400,000$. However, the results are still interesting, since the fraction answering $\$ 400,000$ (the official correct answer) drops precipitously with age. At age 53, 52 percent answer $\$ 400,000$. By age 90 , only 10 percent do.

\section{II.B. Evidence from ADAMS Data}

The Aging, Demographics, and Memory Study (ADAMS) of the National Institute on Aging conducts in-person clinical assessments of cognitive function and dementia for a subsample of HRS respondents (Langa and others 2005). The ADAMS uses a much smaller sample than the HRS. Only 856 respondents were surveyed in the initial 2002 ADAMS wave. We use both the 2002 wave and a follow-up wave in 2006.

Figure 5 plots naive and controlled Clinical Dementia Ratings (CDRs) for the ADAMS sample (using just the 2000 wave), using sampling weights to correct for overrepresentation of certain groups. The CDR score is on a 0 -to- 4 scale, where 0 is healthy. A score of $1 / 2$ represents very mild dementia; 1 represents mild dementia; 2 represents moderate dementia; 3 represents 
Figure 5. Clinical Dementia Ratings by Age from the Aging, Demographics, and Memory Study (ADAMS)

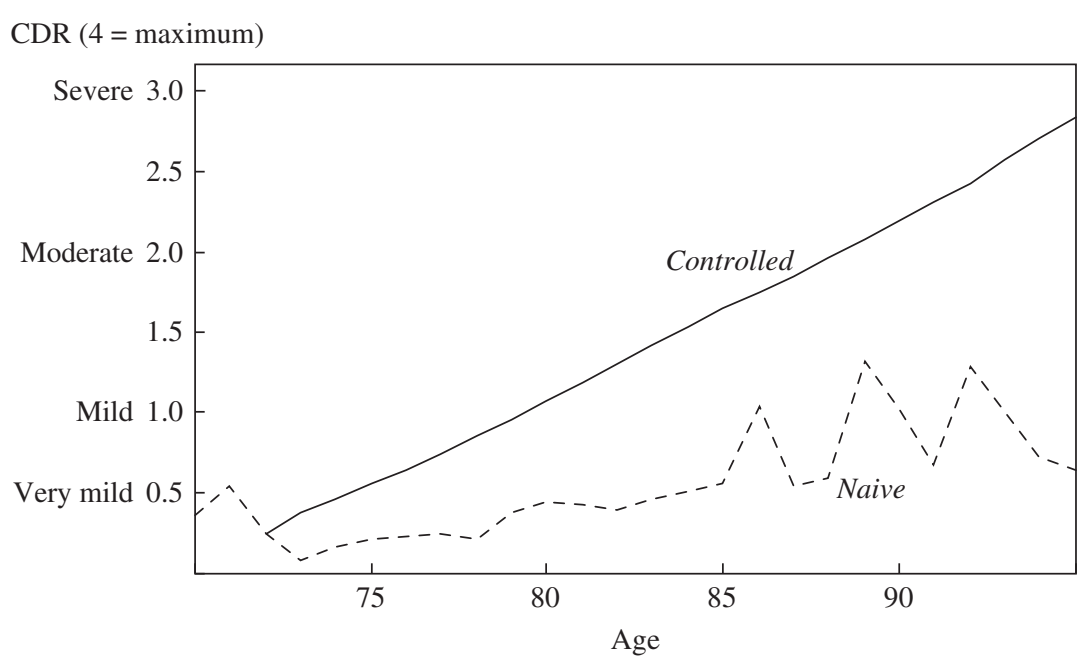

Source: ADAMS data and authors' calculations.

severe dementia; 4 is the highest dementia rating on the scale. ${ }^{9}$ Scoring is done by a panel of clinicians who base their judgments on the entire battery of tests in the ADAMS. Hence, the CDR has a very high signal-to-noise ratio, since the CDR score is derived from hundreds of survey questions posed to a respondent and his or her caregivers. At age 75 the average score is 0.4 , which is near the threshold for "very mild" dementia. At age 99 the average (control) score is 3.2 , implying that the average respondent has severe dementia.

Note that figure 5 shows a large gap between the naive average and the controlled average CDR scores. The naive averages are highly misleading, since they are affected by selection bias.

\section{II.C. Summary of Evidence from the HRS}

The HRS data paint a clear picture of declining cognitive function with age. They also suggest that selection effects may be more important than cohort effects. Cohort effects are predicted to cause the naive profiles to fall more steeply than the control profiles, since older cohorts have fewer educational advantages. Selection effects, in contrast, should cause the

9. See "Clinical Dementia Rating (CDR) Scale," Washington University, St. Louis (alzheimer.wustl.edu/cdr/PDFs/CDR_OverviewTranscript-Revised.pdf) for a description. 
naive profiles to fall less steeply than the control profiles, since the individuals with the poorest cognitive function tend to exit the sample. Selection bias seems to be more important in the HRS data, since our controlled profiles are steeper than our naive profiles.

\section{Financial Services and Age: Evidence on the Inverse U-Shape of Performance}

In this section we document a U-shaped curve with age in the prices people pay in 10 different types of credit transactions: credit card balance transfer offers, home equity loans, home equity lines of credit, automobile loans, mortgages, personal credit cards, small business credit cards, credit card late payment fees, credit card overlimit fees, and credit card cash advance fees. We discuss three forms of prices paid: interest rates (measured as annual percentage rates, or APRs), fee payments, and balance transfer costs.

In each case we conduct a regression analysis that identifies age effects and controls for observable factors that might explain the patterns by age. Thus, unless otherwise noted, in each context we estimate a regression of the following type:

$$
F=\alpha+\beta \times \text { spline(age })+\gamma \times \text { controls }+\varepsilon,
$$

where $F$ is a measure of the price paid by the borrower (for example, the APR), "controls" is a vector of control variables intended to capture alternative explanations in each context (for example, measures of credit risk), and "spline(age)" is a piecewise linear function that takes the consumer's age as its argument, with knot points at ages 30, 40, 50, 60, and 70 . We then plot the fitted values for the spline on age, computing the intercept using the sample means for the controls. The regressions are either pooled panel or cross-sectional regressions, depending on the context. ${ }^{10}$

Below we discuss the nature of the products and the prices paid, present graphs of fitted values on the spline coefficients, and discuss possible explanations for our findings. We describe the data in the appendix and provide summary statistics for the datasets and the regression results in the online appendix. ${ }^{11}$

10. As variants, we tried having knot points at every five years, and replacing the spline with a set of dummy variables for age. The results were qualitatively and quantitatively similar, also showing a U-shaped pattern by age.

11. Online appendices for all papers in this issue may be found on the Brookings Papers webpage (www.brookings.edu/economics/bpea) under "Conferences and Papers." 


\section{III.A. Three Financial Choices}

We first examine three of the above financial transactions: credit card balance transfer offers, home equity loans, and home equity lines of credit. The U-shaped pattern by age for suboptimal balance transfer behavior is a relatively clean example and thereby merits special emphasis. In the other two cases we are able to tease out the mechanism leading to higher interest payments for younger and older borrowers, namely, mistakes made in estimating the value of one's home.

EUREKA MOMENTS: OPTIMIZING THE USE OF CREDIT CARD BALANCE TRANSFERS. Credit card holders frequently receive offers to transfer account balances from an existing card to a new card charging a substantially lower APR for an initial period from six months to a year or more (a "teaser" rate). The catch is that all payments on the new card are applied first to the transferred balance, and to new purchases (which are subject to a higher APR) only after the transferred balance has been paid off.

The optimal strategy for the cardholder during the teaser-rate period, then, is to make all new purchases on the old credit card and none on the new card until all the transferred balances have been paid off. We categorize cardholders in our dataset by the speed with which they converge on this optimal strategy. Some (about one-third) identify this optimal strategy immediately, before making any purchases with the new card. Others (slightly more than one-third) never identify the optimal strategy during the teaser rate period. The remaining third discover it after one or more billing cycles as they observe their surprisingly high interest charges. These borrowers make purchases for one or more months and then have a "eureka" moment, after which they implement the optimal strategy. ${ }^{12}$

The top panel of figure 6 plots the frequency of eureka moments for each of five age groups. The plot of those who never experience a eureka moment shows a pronounced U-shape by age; in contrast, the plot of those who implement the optimal strategy immediately has a pronounced inverted U-shape. Plots for eureka moments in the interior of the time space (that is, those that occur strictly after the first month) are flat. ${ }^{13}$ The "No eureka" line implies that the groups with the greatest frequency of maximal confusion

12. We thank Robert Barro of Harvard University for drawing our attention to this type of potentially tricky financial product. We also note that changes in regulation proposed in May 2008 by the Federal Reserve, the National Credit Union Administration, and the Office of Thrift Supervision would forbid banks from applying payments solely to transferred balances.

13. Although the average share of borrowers in each of the intermediate categories is small—on the order of 5 percent—summing over all the months yields a fraction of borrowers equal to one-third of the total. 
Figure 6. "Eureka" Moments in Credit Card Balance Transfers by Age of Borrower Fraction of borrowers experiencing eureka moment ${ }^{\mathrm{a}}$
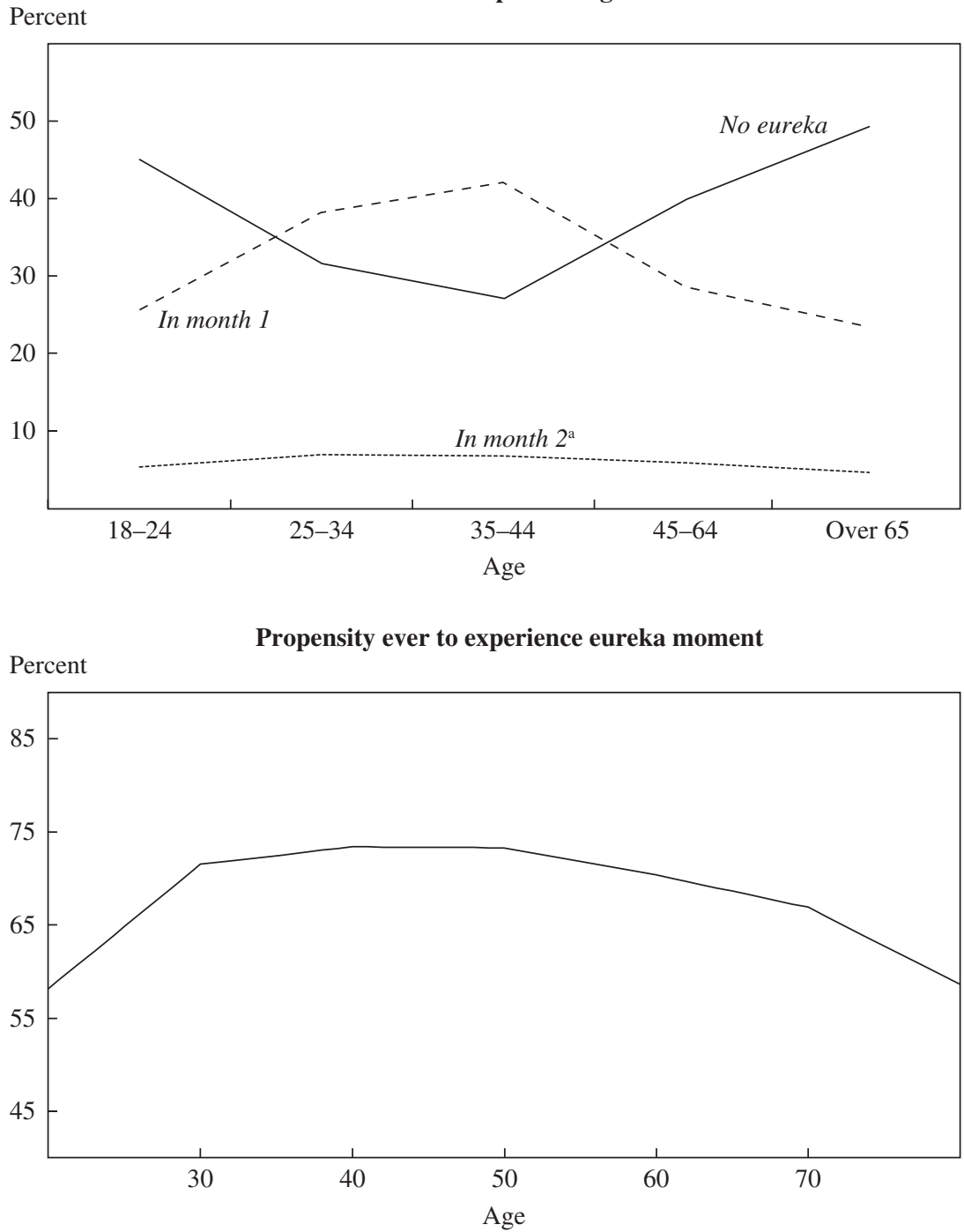

Source: Authors' calculations.

a. Fraction experiencing eureka moment in each of months 3 through 6 is below 10 percent for all ages. 
are younger adults and older adults. The group most likely to adopt the optimal strategy immediately is adults aged 35-44.

The bottom panel of figure 6 plots the fitted values of the age splines for the propensity ever to experience a eureka moment. Note that unlike in the other figures, higher values here indicate a smaller propensity to make mistakes. Consistent with the evidence so far, a performance peak occurs in middle age.${ }^{14}$ In section III.C we discuss possible explanations for this and the other age-related differences we observe. ${ }^{15}$

HOME EQUITY LOANS AND LINES OF CREDIT. Figure 7 plots the fitted values on the splines for age for interest rates paid on home equity loans and lines of credit. The lines have a pronounced U-shape: the relatively young and the relatively old face APRs that can be 50 basis points or more higher than what the middle-aged pay.

For these two examples, we believe we understand the mechanism leading to the differences by age: misestimation of the value of one's home. The amount of collateral offered by the borrower, as measured by the loanto-value (LTV) ratio, is an important determinant of loan APRs. Higher LTV ratios imply higher APRs, since the fraction of collateral is lower. At the financial institution that provided our data, borrowers first estimate their home's value and then apply for a loan or credit line falling into one of three categories depending on the implied LTV estimate: 80 percent or less, between 80 and 90 percent, and 90 percent or greater. The financial institution then independently verifies the home's value using an industry-standard methodology and constructs its own LTV measure, which can therefore differ from the borrower's. ${ }^{16}$

The pricing of the loan or credit line depends on the LTV category that the borrower falls into, and not on where precisely the LTV falls within that category. ${ }^{17}$ If the borrower has overestimated the value of the home,

14. We also check for the possibilities that the relatively old and the relatively young might have lower levels of debt or less access to credit than the middle-aged. We find that neither credit card debt nor the number of open credit cards varies in economically or statistically significant ways with age.

15. The online appendix presents a formal hypothesis test for the U-shaped curves; we reject the null hypothesis of a flat age-based pattern in 9 out of the 10 cases.

16. Agarwal (2007) provides evidence that younger households are more likely to overstate, and older households to understate, their home's value. Bucks and Pence (2006) present evidence that many borrowers do not accurately estimate their home's value.

17. We have verified this practice in our dataset by regressing the APR on both the bank's estimated LTV and dummy variables for whether the bank's LTV falls into one of the three categories. Only the coefficients on the dummy variables were statistically and economically significant. Ben-David (2008) also shows that there are discrete jumps in lending rates at LTV cutoff points. 
Figure 7. Interest Rates Offered on Home Equity Loans and Lines of Credit by Age of Borrower

Annual percentage rate (APR)

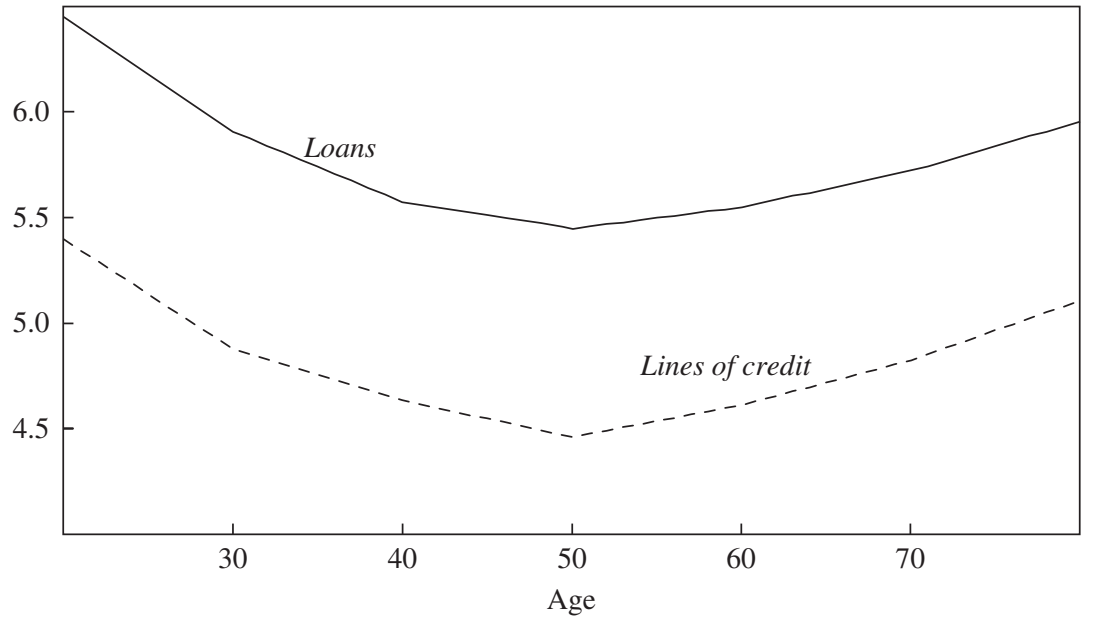

Source: Authors' calculations.

so that the financial institution's LTV is higher than the borrower's, the institution will direct the buyer to a different loan with a higher interest rate corresponding to the higher LTV. In such circumstances the loan officer is also given some discretion to depart from the financial institution's normal pricing schedule to offer a higher interest rate than the officer would have offered to a borrower who had correctly estimated her LTV. If the borrower has underestimated the home's value, however, the financial institution need not direct the buyer to a loan with a lower interest rate corresponding to the financial institution's lower LTV estimate; the loan officer may simply choose to offer the higher interest rate associated with the borrower's estimate. ${ }^{18}$

Since the APR paid depends on the LTV category and not on the LTV itself, home value misestimation leads to higher interest rate payments only if the financial institution's estimated LTV falls in a different category than the borrower's. If, in contrast, the borrower's estimated LTV was, say, 60 percent, but the financial institution's estimate was 70 percent, the borrower would still qualify for the highest-quality loan category

18. Even if the financial institution's estimate of the true home value is inaccurate, that misestimation will not matter for the borrower as long as other institutions use the same methodology. 
(LTV $<80$ percent) and would not suffer an effective interest rate penalty. We define a rate-changing mistake (RCM) to have occurred when the borrower's LTV falls in a different category from the financial institution's, for instance when the borrower estimates an LTV of 85 but the financial institution calculates an LTV of 75 percent (or vice versa). We find that, on average, making an RCM increases the APR by 125 basis points for loans and 150 basis points for credit lines (controlling for other variables, but not age).

To examine the importance of RCMs, we first study the APRs offered to consumers who do not make an RCM. The top panel of figure 8 plots the fitted values from reestimating the regressions of APRs on borrower characteristics and age splines, but now conditioning on borrowers who do not make an RCM. The plots show only slight differences in APR paid by age. For home equity loans, the difference in APR between a borrower at age 70 and a borrower at age 50 has shrunk from 36 basis points to 8 basis points; for home equity lines of credit, it has shrunk from 28 basis points to 4 basis points. For a borrower at age 20, the APR difference over a borrower at age 50 has shrunk to 3 basis points for both loans and lines of credit. We conclude that among borrowers who do not make an RCM, the APR is essentially flat with age. Therefore, the U-shape of the APR age curve is primarily driven by RCMs.

We next investigate who makes RCMs. The bottom panel of figure 8 plots the propensity to make an RCM by age for home equity loans and credit lines. The figure shows U-shapes for both. Borrowers at age 70 have a 16-percentage-point greater chance of making a mistake on a home equity loan than borrowers at age 50 (the difference for lines of credit is 19 percentage points); the comparable numbers for borrowers at age 20 relative to age 50 are 35 and 41 percentage points. The unconditional average probability of making an RCM is 24 percent for loans and 18 percent for credit lines.

This age effect is consistent with the cost of an RCM calculated above and the additional probability of making an RCM with age. For example, as noted, a 70-year-old has a 16-percentage-point additional chance of making an RCM on a home equity loan. Multiplying this by the average APR cost of an RCM for home equity loans of about 125 basis points gives an expected incremental APR paid of about 26 points. The analogous difference for lines of credit is 23 basis points. These differences are very close to the estimated differences of about 23 and 28 basis points.

We conclude that in this example we have identified the reason for the U-shape of home equity APRs as a function of age (as always, controlling for other characteristics). Younger and older consumers have a greater tendency to misestimate the value of their home, which leads them to make 
Figure 8. Rate-Changing Mistakes in Home Equity Loan and Line of Credit Applications by Age of Borrower

\section{Percent}

APRs for borrowers who do not make an $\mathbf{R C M}^{\mathrm{a}}$

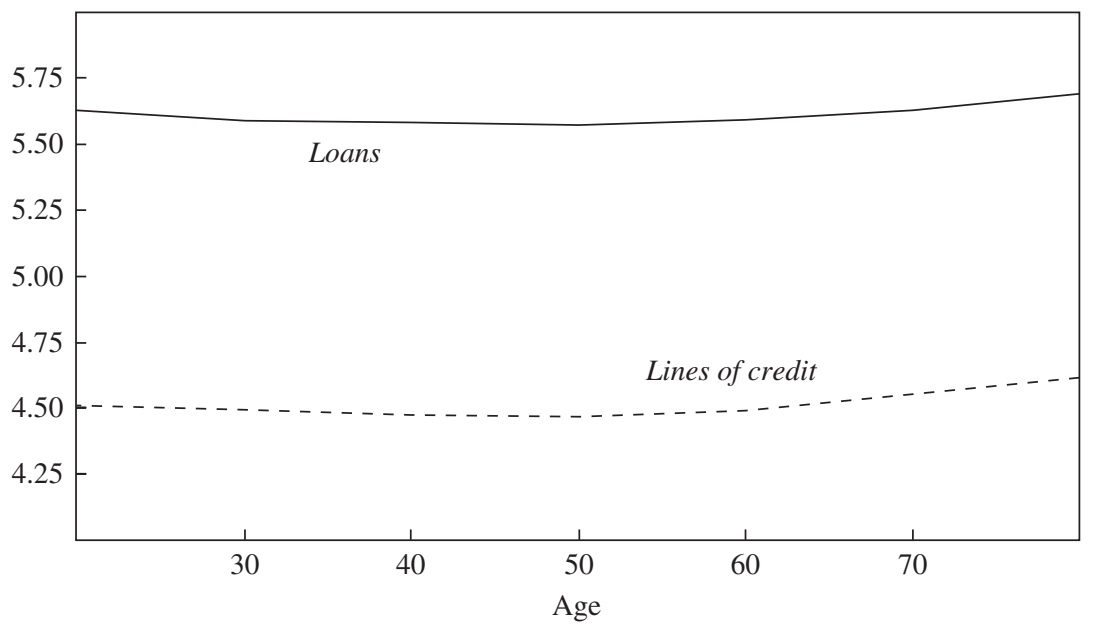

Percent

Propensity to make an RCM

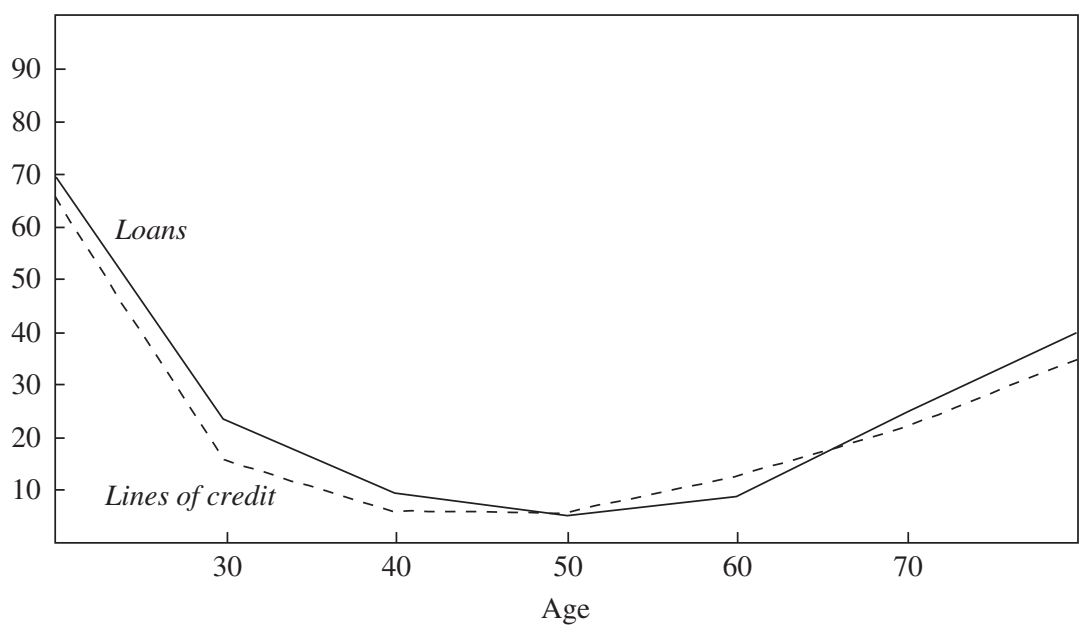

Source: Authors' calculations.

a. A rate-changing mistake (RCM) occurs when the borrower's estimate of the value of the home differs from the lender's estimate by enough to place the borrower's implied loan-to-value (LTV) ratio in a different interest rate category from the lender's implied LTV. The categories are LTV $\leq 80$ percent, 80 percent $<\mathrm{LTV}<90$ percent, and LTV $\geq 90$ percent; loans in higher LTV categories may be charged higher interest rates. 
an RCM, which in turn results in their borrowing at a higher APR than they could have obtained. On the other hand, for consumers who do not make an RCM, the APR is essentially independent of age.

Given the large costs associated with an RCM, one might ask why borrowers do not make a greater effort to accurately estimate the value of their home. One possibility is that potential borrowers are not aware that credit terms will differ by LTV category or, if they are aware of this fact, they may not know by how much the terms differ. This feature of loan pricing may thus be a shrouded attribute, in the sense of Gabaix and Laibson (2006).

\section{III.B. Seven Other Financial Choices}

In this section we present results on the seven other credit prices we studied: interest rates on personal credit cards, auto loans, mortgages, and small business credit cards (figure 9), and three types of credit card fees (late payment, overlimit, and cash advance; figure 10). In all seven cases, plots of fitted values on the coefficients on the age splines are U-shaped by

Figure 9. Interest Rates Paid by Type of Loan and Age of Borrower

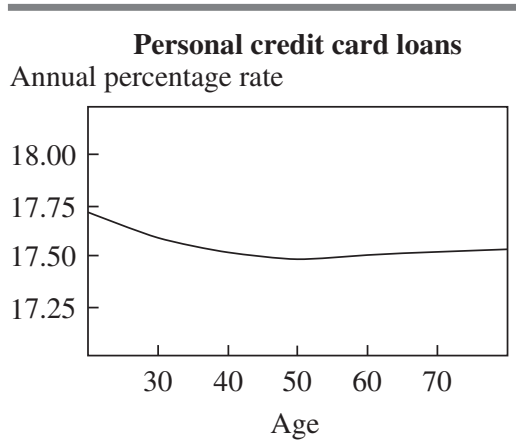

Automobile loans

Annual percentage rate

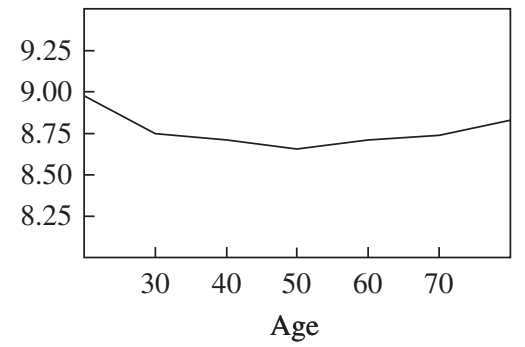

Mortgages

Annual percentage rate

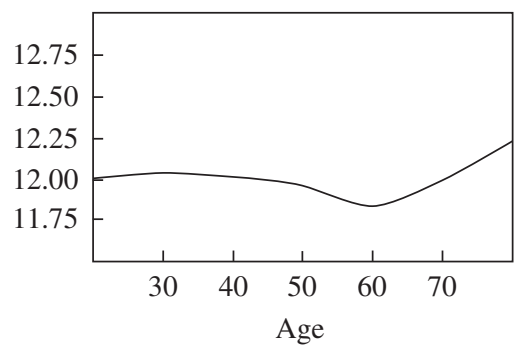

Small business credit card loans Annual percentage rate

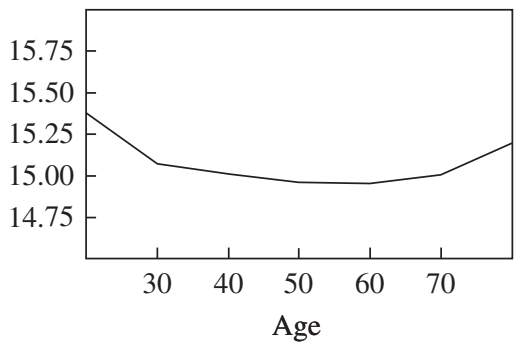

Source: Authors' calculations. 
Figure 10. Incidence of Credit Card Fees by Age of Borrower

No. of fees incurred per month

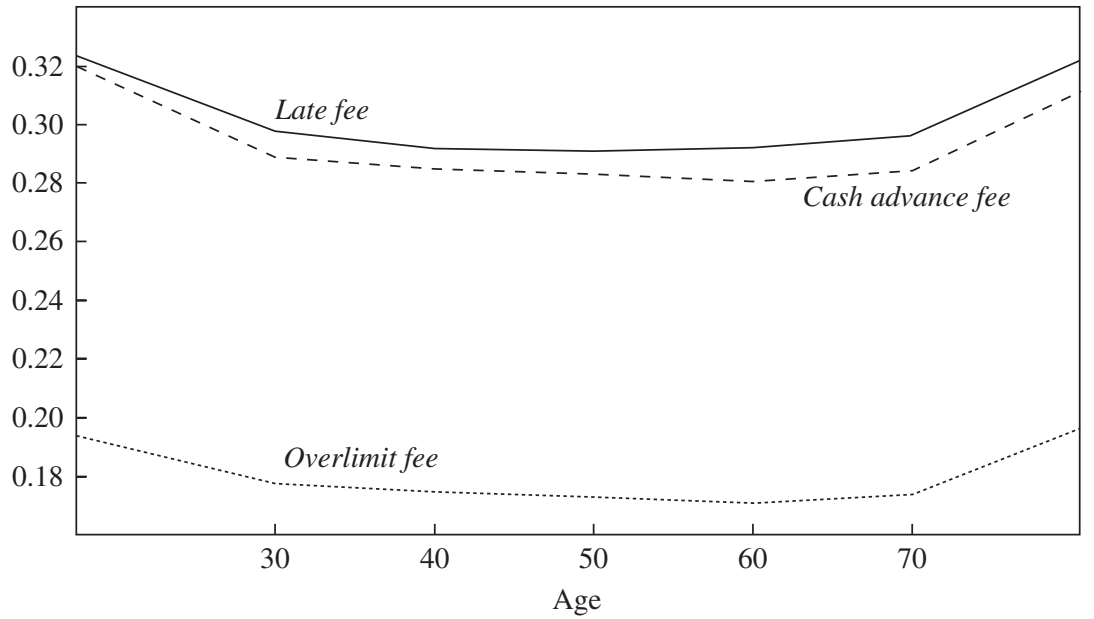

Source: Authors' calculations.

age, although the amplitudes vary. In each case, in the underlying regressions we have tried to control for other variables that might explain differences in the cost of suboptimal financial choices by age. Data and regression results are presented in the online appendix.

Visual inspection of the age splines in all cases suggests that fees and interest rates paid are lowest for customers in their late 40s or early 50s. To estimate the minimum more precisely, we reestimate each model, replacing the splines from age 40 to 50 and from age 50 to 60 with a single spline running from age 40 to 60 and the square of that spline. Table 2 reports our estimates of the "age of reason," the point in the life span at which financial mistakes are minimized, for each type of transaction. The mean age of reason in these estimates is 53.3 years, and the standard deviation calculated by treating each study as a single data point is 4.3 years.

The lowest age of peak performance is that for the eureka moment task. Interestingly, that task is arguably the most dependent on analytical capacity and the least dependent on experience, since the kinds of balance transfer offers that we study were new financial products when our data were collected. Hence, it is not surprising that the peak age for succeeding at that task would be earlier than for the other tasks. However, since we lack a rigorous measure of the difficulty of a task, the interpretation of the eureka case remains speculative. 
Table 2. Age of Peak Performance for 10 Financial Tasks

\begin{tabular}{lcc} 
& \multicolumn{2}{c}{ Age } \\
\cline { 2 - 3 } Task & Mean & Standard deviation \\
\hline Minimizing APR on: & 55.9 & 4.2 \\
$\quad$ Home equity loans & 53.3 & 5.2 \\
Home equity lines & 50.3 & 6.0 \\
Credit cards & 49.6 & 5.0 \\
Automobile loans & 56.0 & 8.0 \\
Mortgages & 61.8 & 7.9 \\
Small business credit cards & 45.8 & 7.9 \\
Experiencing eureka moment & 51.9 & 4.9 \\
Avoiding credit card late fees & 54.0 & 5.0 \\
Avoiding credit card overlimit fees & 54.8 & 4.9 \\
Avoiding credit card cash advance fees & 53.3 & 4.3 \\
Average & &
\end{tabular}

Source: Authors' calculations.

It would be useful to measure such effects in other decision domains, such as savings choices, asset allocation choices beyond stocks, and health care choices. We have described a simple procedure for doing this: first identify the general shape of the age effect, as in equation 1, using controls and age splines, and then estimate a linear-quadratic equation to localize the peak of performance. George Korniotis and Alok Kumar (forthcoming-a) confirm our U-shape hypothesis in their study of investment skills.

It may also be possible to develop models that predict the age of peak performance. There is a growing consensus that analytically intensive problems, like those in mathematics, are associated with younger peak ages (see Simonton 1988; Galenson 2006; Weinberg and Galenson 2005). Analogously, problems that require more experiential training have older peak ages. For instance, Benjamin Jones (2005) finds that the peak age for natural scientists drifted higher over the 20th century. Relative to 100 years ago, more experience now needs to be accumulated to reach the cutting edge of scientific fields. In this paper we found that what is arguably the most analytically demanding task-deducing the best way to exploit lowinterest balance transfers-is associated with the youngest age of peak performance. It would be useful to study the association between analytically demanding problems and peak age.

\section{III.C. Possible Explanations}

Each credit market has idiosyncratic factors that may contribute to the hump-shaped age patterns that we have measured. But the recurrence of 
that pattern across all 10 outcomes above suggests that there may also be some common underlying explanation. In this section we discuss several such possible explanations, including cognitive age effects, selection effects, and cohort effects. We do not find evidence for selection or cohort effects that could explain our results, but our data do not allow us to definitively rule them out.

AGE-RELATED EFFECTS. One possible explanation for the U-shaped pattern of mistakes is a combination of two age-based effects: diminishing returns to learning, and the age-based decline in analytical function we documented in section I. Relatively young borrowers tend to have low levels of experience but a high degree of analytical function, whereas older borrowers tend to have high levels of experience but relatively lower analytical function. We discussed these mechanisms in section I and explained how these offsetting trends could produce a hump-shaped pattern in financial sophistication.

This hypothesis of two offsetting age-based effects also provides a possible explanation of the location of peak performance. We hypothesize that peak performance reflects a trade-off between rising experience and declining analytical function. If so, the sooner people start experimenting with a financial product, the earlier the peak of performance should be. To evaluate this hypothesis for each financial product, we first construct the age distribution of the users of this product in our dataset and calculate the age at the 10th percentile of the distribution, which we call "age ${ }_{10 \%}$." This is a proxy for the age at which people typically start using the product. We then regress the location of peak performance on that variable, with the following results:

$$
\text { peak }=33+0.71 \times \text { age }_{10 \%} .
$$

The adjusted $R^{2}$ for the equation is 0.62 , and the standard errors on the intercept and the coefficient are, respectively, 5.7 and $0.19 .{ }^{19}$ Thus, we reject the null hypothesis of no relationship between the peak variable and age $\mathrm{e}_{10 \%}$. Products whose use begins later in life tend to have a later performance peak.

SELECTION EFFECTS. The cross-sectional age effects that we measure are probably also partly attributable to differences in the pool of borrowers by age group - a selection effect. For example, in the total population of U.S. households, retirees borrow less than other adults, as the life-cycle

19. The effect is robust to the choice of percentiles other than the 10th for the start variable. For instance, the correlation between peak age and median age of users for the product is 0.83 . 
consumption model predicts. Older adults who are borrowing may therefore be unrepresentative of the population of all older adults. Likewise, older adults who are borrowing might be less financially savvy than 30- or 50 -year-old borrowers, since borrowing might be less of a bad signal at these younger ages. ${ }^{20}$ Below we describe several ways of measuring the role of sample selection in determining our results.

Lack of financial sophistication in relatively older (or younger) borrowers should be reflected in those borrowers having less education, income, or net worth than nonborrowers of the same age. To make such comparisons, we calculate for each age group the ratio of the median educational attainment (or income, or net worth) of borrowers in that group to the median for all members of the group. We want to determine whether these ratios differ across age groups. In other words, are borrowers differentially selected across different age groups? Since our proprietary dataset contains information only on borrowers, we cannot use it to make these calculations. However, we can make such comparisons using the SCF.

Using data from the 1989, 1998, 2001, and 2004 SCFs, we compute the above ratios for education, income, and net worth; results are presented in the online appendix. We find that within age groups, borrowers almost always have higher income and more education than the population as a whole, and often have higher net worth. Moreover, older borrowers appear to have relatively higher income and more education relative to their peers than middle-aged borrowers do. Hence, these data suggest that the selection effects by age go in the opposite direction from that predicted: older borrowers appear to be a more affluent and better educated pool than middle-aged borrowers. We present additional results in the online appendix showing that borrowing by age does not appear to vary by race, and that older borrowers do not appear to have disproportionately lower incomes, lower FICO (credit) scores, or more debt than older people generally.

None of these analyses lend support to the idea that sample selection effects contribute to the U-shaped patterns that we see in the data. If in fact a higher proportion of older borrowers are unsophisticated, then that lack of sophistication is somehow evident only in borrowing rates and fee payments, and not in credit scores, default rates, educational attainment, income, or net worth. Although we concede that this is a logical possibility, we know of no explanation for why such a lack of sophistication would appear so selectively in the data.

20. They could also be riskier, in ways not captured by the risk measures we include-a hypothesis that we consider (and reject) below. 
COHORT EFFECTS. Older borrowers in our cross section might make relatively less sophisticated financial choices than younger borrowers because they belong to cohorts that have less human capital than younger cohorts (see, for example, Flynn 1984). For example, older cohorts may be less mathematically literate than younger cohorts, or they may use less sophisticated search technologies: for instance, they may be less inclined to use the Internet to compare financial products. Finally, older cohorts may have grown up with different financial products than those now available.

Without a true panel dataset with information going back 20 years or more, we cannot measure the role of cohort effects in explaining the observed U-shaped pattern relative to other explanations. However, several facts make us think that cohort effects cannot be the whole explanation. First, education-based cohort effects cannot explain the pattern of declining mistakes that we observe over the first half of adulthood. Second, we observe the U-shaped pattern over a broad range of products, some of which, such as mortgages, have seen substantial changes in their institutional characteristics over time, while others, such as auto loans, have not. Third, if cohort effects were important, one would expect to see differences in prices paid between male and female borrowers, on the grounds that the current cohort of older female borrowers have tended to be less involved in financial decisionmaking than their male contemporaries. In fact, we find no substantive differences between men and women. Finally, for two products - auto loans and credit cards - we have data from 1992, 10 years earlier than the data used for our other studies. Replicating our analysis for these data results in the same U-shaped pattern.

In summary, although cohort effects are probably present in our data, we doubt that they play an important role in explaining the U-shaped pattern. Cohort effects are most likely to make some contribution to the decline in performance that we measure after middle age. The improvement in performance up to middle age is harder to explain with cohort stories, although some preference-based cohort effect might be generating this pattern. ${ }^{21}$

RISK EFFECTS. Some of our results could be driven by unobserved variation in default risk that is not reflected in the risk measures (such as FICO scores) that we use as control variables. For instance, the U-shaped pattern of APRs could be due to a similar pattern of default by age. We test this alternative hypothesis by analyzing default rates on credit cards, auto loans, and home equity loans and credit lines. We estimate a linear regression in

21. See Malmendier and Nagel (2007) for examples of how cohort effects affect preferences for equities. 
which the default rate is modeled as a weighted sum of an age spline, log income, and all of the standard risk measures that are in our data. When we plot fitted values by age (see the online appendix for the chart), we find a pronounced inverted U-shape for home equity loans and credit lines, implying that the young and the old have lower default rates than the middle-aged. Credit cards and auto loans show a slightly inverted U-shape, and the curve for small business credit cards is about flat. Hence, these results contradict the hypothesis that our APR results are driven by an unmeasured default risk. Finally, note that age-dependent default risks would not explain the observed patterns in credit card fee payments or in the suboptimal use of credit card balance transfers.

OPPORTUNITY COST OF TIME. Some age effects could be generated by age-related variation in the opportunity cost of time (Aguiar and Hurst 2007). However, standard opportunity cost effects would predict that retirees pay lower prices, which is not what we observe in our data. Nevertheless, our findings and those of Aguiar and Hurst are not necessarily contradictory. Shopping for a familiar commodity-for instance, a gallon of milk-is much less analytically demanding than shopping for a complicated and somewhat unfamiliar product that can differ across many dimensions, such as a mortgage. Hence, we are not surprised to see older adults shopping more effectively for food even while losing ground in relatively more complex domains. In addition, shopping at stores and supermarkets may be a more pleasant activity than shopping at banks and other lenders, leading consumers to devote more time to the former.

The 2007 SCF provides some support for the idea that shopping intensity for loans decreases with age. That survey asked borrowers whether, when borrowing money or obtaining credit, they shop around a great deal, moderately, or not at all. For borrowers under age 35, 24 percent report shopping around a great deal, 60 percent moderately, and 15 percent almost no shopping. The corresponding figures for those aged 75 and over are 15 percent, 40 percent, and 46 percent. The online appendix presents a full table of results by SCF age class as well as the text of the survey question.

DISCRIMINATION AND OTHER SUPPLY FACTORS. The presence of age effects might also be interpreted as evidence for some kind of age discrimination. Banks may explicitly choose to charge older and younger borrowers higher APRs, or they may simply market products that happen to have higher APRs or fees more aggressively to the young or the old. We believe these explanations to be unlikely for two reasons. First, the U-shaped pattern shows up in contexts, such as credit card fee payments and failures to optimally use balance transfer offers, in which discrimination is not rele- 
Table 3. Differences in the Cost of Selected Financial Products by Age

\begin{tabular}{|c|c|c|c|c|}
\hline \multirow[b]{2}{*}{ Product or task } & \multicolumn{2}{|c|}{$\begin{array}{l}\text { Interest rate or } \\
\text { probability difference } \\
\text { relative to age } 50^{\mathrm{a}}\end{array}$} & \multicolumn{2}{|c|}{$\begin{array}{l}\text { Total cost difference } \\
\text { relative to age } 50^{\mathrm{b}} \\
\quad \text { (dollars a year) }\end{array}$} \\
\hline & At age 25 & At age 75 & At age 25 & At age 75 \\
\hline Product & \multicolumn{2}{|c|}{$\begin{array}{l}\text { Difference in APR } \\
\quad \text { (basis points) }\end{array}$} & & \\
\hline Home equity loan & 73 & 40 & 284 & 146 \\
\hline Home equity line of credit & 68 & 51 & 296 & 265 \\
\hline Auto loan & 20 & 12 & 8 & 4 \\
\hline Mortgage & 6 & 15 & 25 & 62 \\
\hline Personal credit card & 17 & 5 & 2 & 1 \\
\hline \multirow[t]{2}{*}{ Small business credit card } & 26 & 14 & 3 & 2 \\
\hline & \multicolumn{2}{|c|}{$\begin{array}{l}\text { Difference in probability } \\
\text { of experiencing }\end{array}$} & & \\
\hline Eureka moment & 8 & 11 & 37 & 13 \\
\hline Avoiding credit card late fees & 2 & 2 & 8 & 8 \\
\hline Avoiding credit card overlimit fees & 1 & 1 & 4 & 4 \\
\hline Avoiding credit card cash advance fees & 2 & 1 & 8 & 4 \\
\hline
\end{tabular}

Source: Authors' calculations.

a. For the six products, difference between the APR paid by a borrower of the indicated age and that of a 50-year-old borrower. For the four tasks, difference between the probability that a borrower of the indicated age will succeed at the task and the same probability that a 50-year-old will.

b. For the six products, the difference in APRs times the average debt level by age (see the online appendix). For the eureka moment, the difference in probability times the APR difference for personal credit cards times the balance transferred. For the credit card fees, the difference in probability times $\$ 35$ (the typical fee amount) times 12 months. This may understate the true cost difference because multiple fee payments may trigger a rise in the interest rate on cash advance balances.

vant, since the products are the same and all cardholders face the same rules. Second, firms are likely to avoid age discrimination for legal reasons or to avoid the costs of negative publicity. ${ }^{22}$

\section{III.D. How Large Are the Effects?}

The effects we find have a wide range of dollar magnitudes, as reported in table 3. We estimate that for home equity lines of credit, 75 -year-olds pay about $\$ 265$ more a year, and 25-year-olds about $\$ 296$ more, than 50 -year-olds. For other quantities, such as credit card fees, the implied age differentials are small: up to $\$ 10$ a year for each kind of fee. The importance of these effects goes beyond the economic significance of

22. Charles, Hurst, and Stephens (2008) document racial differences in lending rates at auto finance companies, but not at banks. 
each individual case, however: the consistent appearance of a U-shaped pattern of costs in such a wide variety of circumstances points to a phenomenon that might also apply to many other areas. ${ }^{23}$ An important question is whether this pattern translates into other choice domains, including saving, asset allocation, and health care.

Indeed, in domains for which we lack data, the effects might be larger. For instance, our sample probably does not contain older adults with severe dementia, for which the effects might be stronger. In section VI we estimate the fraction of GDP that may be wasted because of poor financial decisionmaking.

\section{Other Work on Economic Decisionmaking over the Life Cycle}

Our analysis is part of a recent literature that studies the effects of aging and cognitive function on the use of financial instruments (see, for example, Willis 2007; McArdle and others forthcoming), which in turn is part of a broader literature on household finance (Campbell 2006). In their work on financial literacy, Annamaria Lusardi and Olivia Mitchell (2006, 2007) find declines in the mastery of basic financial concepts, such as the ability to calculate percentages or perform simple division, in adults after age 50 .

In light of our findings, other researchers have offered to look for age patterns of financial mistakes in their own datasets. Lucia Dunn (personal communication, June 2007) has reported to us that the Ohio State Survey on credit cards shows a U-shaped pattern of credit card APR terms by age. Fiona Scott Morton (personal communication, May 2007) has reported that in her dataset of indirect auto loans (loans made by banks and finance companies using the dealer as an intermediary; see Scott Morton, Zettelmeyer, and Silva-Risso 2003), loan markups show a U-shaped age pattern. Luigi Guiso (personal communication, April 2007) finds that when picking stocks, consumers achieve their best Sharpe ratios at about age 43, and this effect appears to be entirely driven by the willingness to hold stocks in the first place. Ernesto Villanueva (personal communication, April 2007) finds that mortgage APRs in Spanish survey data (comparable to the U.S. Survey of Consumer Finances) follow a U-shaped curve by age.

A relationship between age and performance has been noted in many nonfinancial contexts. Survey data suggest that labor earnings peak around

23. For example, Korniotis and Kumar (2008a) confirm our U-shape hypothesis in their study of investment skills. 
age 50 (Gourinchas and Parker 2002), or after about 30 years of work experience (Murphy and Welch 1990). Kelly Shue and Erzo Luttmer (2009) find that older and younger voters make disproportionately more errors in voting than do middle-aged voters. John Graham, Campbell Harvey, and Manju Puri (2008) find that older CEOs tend to be more risk averse (see Simonton 1988 for a survey).

A recent literature reports systematic differences in rationality between groups of people, particularly with respect to financial decisionmaking. Barry Scholnick, Nadia Massoud, and Anthony Saunders (2008) find that wealthier people make fewer mistakes on their credit cards, and Agarwal and others (2008) reach a similar conclusion concerning more experienced people. Victor Stango and Jonathan Zinman (2009) document that naive consumers substantially underestimate loan interest rates when asked to infer them from principal, maturity, and monthly payments. Korniotis and Kumar (2008) find that investors who perform better on standard intelligence tests obtain better risk-adjusted returns (see also Korniotis and Kumar forthcoming-b). In experimental contexts, Shane Frederick (2005) identifies a measure of IQ: people with higher scores on cognitive ability tasks tend to exhibit fewer and weaker psychological biases. Daniel Benjamin, Sebastian Brown, and Jesse Shapiro (2006) find that subjects with higher intelligence test scores, or less cognitive load, display fewer behavioral biases.

Several researchers have looked at the response of consumers to credit card teaser rates. Haiyan Shui and Lawrence Ausubel (2005) show that consumers prefer credit card contracts with low initial rates for a short period to ones with somewhat higher rates for a longer period, even when the latter are ex post more beneficial. Consumers also appear reluctant to switch contracts even when they would benefit from doing so (Agarwal and others 2006). Stefano DellaVigna and Ulrike Malmendier (2004) theorize that financial institutions set the terms of credit card contracts to reflect consumers' poor forecasting ability over their future consumption. Many of these effects are discussed in the literature on behavioral industrial organization, which documents and studies markets with boundedly rational consumers and rational firms. ${ }^{24}$ In some of that literature, the effects depend on having both naive and sophisticated consumers in the market. The present paper suggests that those naive consumers will disproportionately be younger and older adults.

24. Examples from this literature include DellaVigna and Malmendier (2004), Gabaix and Laibson (2006), Heidhues and Kőszegi (2009), Malmendier and Shanthikumar (2007), Mullainathan and Shleifer (2005), and Spiegler (2006). 


\section{Regulatory Responses}

In this section we discuss nine mutually compatible policy responses (and some hybrids) to the problems we have identified, both specifically with respect to older adults and more generally with respect to their applicability to financial decisionmakers of all ages. We analyze the pros and cons of each approach without arguing for the adoption of any one of them, recognizing that strong regulatory interventions have the potential to generate large social benefits but also large social costs. The nine approaches are discussed approximately in order from least to most paternalistic. This ordering is somewhat arbitrary since some approaches have multiple dimensions, some of which might be more or less paternalistic than others.

\section{V.A. Laissez-Faire}

Laissez-faire is surely not the first-best policy. As we have noted, about half of decisionmakers between ages 80 and 89 are significantly cognitively impaired. The competitive equilibrium is unlikely to be efficient when agents routinely make significant cognitive errors.

A growing body of anecdotal evidence finds that overpriced financial products are being targeted at older adults (for example, Choi-Allum 2009). The competitive equilibrium works as follows: Some older adults will make bad decisions (for example, overpaying for financial services or losing their money in fraudulent schemes), generating economic rents for those who can exploit these decisions. These rents are partially dissipated, however, because the aggressive or manipulative sales tactics needed to capture them are costly, and because fraudulent sellers face the risk of legal punishment. In equilibrium, the zero-economic-profit condition still applies, but the social allocation is inefficient. To put it more intuitively, when sellers must spend a dollar of their own resources (their time, legal defense fees, and so forth) to convince a pool of older adults to give them a dollar in rent, excess profits will be zero, but there is a social deadweight loss of one dollar. In equilibrium, then, wasteful marketing and bad products will survive even if competition eliminates all excess profits. (See Gabaix and Laibson 2006 for a related argument.)

Laissez-faire policies are nevertheless serious candidates on our list of optimal policies, because the laissez-faire approach could be second-best optimal. Strong regulatory interventions are problematic for many familiar reasons. Regulations are usually administratively costly. They may harm the interests of households who are financially sophisticated or who have sophisticated and trustworthy advisers. Policymakers may have conflicts 
of interest, and even well-intentioned policymakers make mistakes. For all these reasons, we do not rule out laissez-faire policies. In addition, laissezfaire policies are compatible with voluntary advance directives (discussed below), in which rational household members, recognizing the possibility of their own future cognitive decline, set up protective mechanisms ahead of time, in the form of family oversight, competent and trustworthy financial advisers, and formal trusts.

However, such delegation-based solutions are limited by seven factors: the failure to anticipate, when cognitively healthy, the possibility of one's own future cognitive decline; the mistaken belief that one will recognize one's own cognitive decline and respond optimally by progressively delegating decisionmaking as it occurs; procrastination; the difficulties that external parties face in determining when key thresholds of cognitive decline have been crossed, so that control can be transferred efficiently; administrative costs, particularly when the trustee is a third party such as an attorney; a lack of financially sophisticated family members, capable of making good financial decisions on the declining adult's behalf; and a lack of trustworthy family members.

The last of these is particularly important, since, counterintuitively, family members are often a poor choice to play an oversight role. Of course, altruism is strong in many families, and many family members do have intimate knowledge of each other's preferences. However, family members also face a conflict of interest when they are residual claimants on a parent's estate. Hence, many older adults will lack an unconflicted, lowcost agent to whom they can safely delegate decisionmaking authority.

\section{V.B. Disclosure}

Full and fair disclosure has been the primary goal of financial regulatory systems since the 19th century, and it is at the heart of many current congressional proposals. Legislation to strengthen disclosure requirements has recently been introduced in many different domains, including mutual fund fees, 401(k) fees, and mortgage origination fees.

However, we are skeptical that improved disclosure will be effective in improving financial choices. Even for cognitively healthy populations, there is scant evidence that increases in disclosure improve decisionmaking. In a series of recent studies of middle-aged adults, additional disclosure and consumer education made surprisingly little difference. In one study, employees with low saving rates were randomly assigned to a treatment in which they were paid $\$ 50$ to read a short survey explaining their 401(k) plan, including a calculation of how much money they would 
personally gain by taking full advantage of the employer match. Relative to a control group, this group did not significantly increase its average 401(k) saving rate (Choi, Laibson, and Madrian 2007). The bankruptcy of the Houston-based Enron Corporation and the huge losses suffered by many of its employees who had invested their 401(k)s largely in Enron stock had no effect, despite intense media coverage, on the willingness of newly hired workers at other firms to invest their 401(k) contributions in employer stock. This was true even for newly hired workers at other firms in Houston (Choi, Laibson, and Madrian 2005). Employer-sponsored financial education seminars have been shown to have little effect on 401(k) enrollment (Madrian and Shea 2001b). A new, easy-to-read summary prospectus proposed by the Securities and Exchange Commission (SEC) seems to have no effect on investor choices (Beshears and others 2009a). Finally, making mutual fund fees overwhelmingly salient does not lead investors to minimize them, even when allocating real money among index funds. In one study, subjects were asked to allocate $\$ 10,000$ among four S\&P 500 index funds. To help with their choice, the subjects were told what an index fund is, given a one-page summary sheet comparing the fees of the four index funds, and given the prospectus of each fund. Only 10 percent of the subjects put all $\$ 10,000$ in the fund with the lowest costs (Choi and others 2007).

The subjects of these studies were all adults in the workforce. It is likely that disclosure would be even less effective on retired older adults experiencing significant declines in cognitive function.

We wish to emphasize that we are not opposed to disclosure. There is no evidence that it hurts, and it is certainly possible that it makes a small positive difference. For example, the study using the SEC summary prospectus found that shortening and simplifying mutual fund prospectuses would save paper and printing costs and decision time, even if it had no effect on asset allocation. So when improved disclosure is itself inexpensive or reduces other costs, it is surely a good idea. But one should not expect disclosure to resolve the regulatory concerns raised by the findings in this paper.

\section{V.C. Libertarian Paternalism: Advice, Defaults, and Other Nudges}

In the last decade a growing body of research has suggested that gentle institutional "nudges" can improve behavior without mandating any particular behavior. Richard Thaler and Cass Sunstein $(2003,2008)$ refer to such interventions as "libertarian paternalism," because the social planner is acting paternalistically by nudging behavior in one direction, but simultaneously maintaining a libertarian stance by allowing the actor to reject 
the nudge at minimal cost. Prominent examples of nudges include automatic 401(k) enrollment with an opt-out feature (Madrian and Shea 2001a; Choi and others 2002) and automatic saving rate escalators (Thaler and Benartzi 2004).

In practice, such nudges work when the nudge is aligned with the intentions of the person being nudged, for example when employees want to be enrolled in their company's 401(k) plan but for whatever reason fail to enroll on their own. But nudges are rejected when the nudge is misaligned with those intentions. For example, when workers are automatically enrolled at a saving rate that they deem too high (say, 12 percent of income), almost all opt out (Beshears and others 2009b). Likewise, automatic annuitization of defined-benefit accumulations is often rejected in favor of lump-sum payouts (Mottola and Utkus 2007).

It is also important that those being nudged not be subject to forceful opposing influences. In the case of automatic 401(k) enrollment, workers overwhelmingly perceive that they save too little (Choi and others 2002), and no third party stands to gain a significant rent by convincing them not to enroll. In other words, no third party has a strong incentive to nudge in the other direction.

Unfortunately, benevolent institutional nudges, whether by the government or by other agents, will probably provide little protection for older adults. These benevolent nudges will often be outweighed by malevolent ones emanating from marketers and unscrupulous relatives (see ChoiAllum 2009). Older adults with low financial literacy or significant cognitive impairment may be no match for highly incentivized parties with malevolent interests and ample opportunities to nudge in the wrong direction.

Here, too, we are not opposed to the intervention in principle. Nudges can partly protect older adults and other vulnerable economic agents. However, we suspect that nudges will only be weakly protective in an environment where older adults are soft (and increasingly wealthy) targets for those with conflicts of interest.

\section{V.D. Financial "Driver's Licenses"}

Another set of proposals would require that individuals pass a "license" test before being allowed to make nontrivial financial decisions, such as opting out of "safe harbor" investment products (Alesina and Lusardi 2006; see section V.G below). Such proposals would need to overcome several logistical problems. Can a test be devised that reliably separates qualified from unqualified investors, without generating too many false negatives or false positives? Can it be administered at a reasonable social 
cost? If the test were administered over the Internet, what would prevent coaching by parties with conflicts of interest? Who would be required to take the test? How often would retesting be required? Would it be required often enough to catch people as they transition (often very quickly) into a state of significant cognitive impairment? Would such a test be politically feasible if it primarily targeted older adults?

\section{V.E. Strengthening Fiduciary Responsibilities}

Regulators could also increase the fiduciary duties of individuals who sell financial products. In the extreme, all sales of financial products to individuals could be required to be conducted by an agent with a fiduciary duty toward the buyer.

The word "fiduciary" originates from the Latin words fides and fiducia, which mean, respectively, "faith" and "trust." Under common law, fiduciaries are legally bound to act at all times for the sole benefit and interest of a beneficiary - the principal — and to avoid conflicts of interest and selfdealing. Because of these legal obligations, the principal can trust the fiduciary to do the right thing. In an influential decision, Judge Benjamin Cardozo wrote that a fiduciary "is held to something stricter than the morals of the market place. Not honesty alone, but the punctilio of an honor the most sensitive, is then the standard of behavior." 25

In the United States, many types of advisers-lawyers, guardians, executors, trustees, conservators of estates, corporate directors, corporate officers, and majority shareholders-bear fiduciary duties. Investment advisers also have a fiduciary duty, which is legislated in the Investment Advisers Act of 1940. As we mentioned in the introduction, the Employee Retirement Investment Savings Act (ERISA) imposes a fiduciary duty on employers that sponsor retirement plans, for their decisions that affect plan participants, who in turn have the right to sue over breaches of that duty.

However, many types of financial representatives and salespeople have no legal fiduciary responsibilities, and a substantial fraction of financial services are sold by such agents. For example, an annuity salesperson who cold-calls potential clients may legally receive large commissions (which are often shrouded from the client) for selling them financial products with large markups. Neither these agents nor the registered representatives of securities broker-dealer firms are considered investment advisers, and

25. Alhough Cardozo would eventually sit on the Supreme Court, this landmark decision was handed down during his earlier tenure on the New York Court of Appeals. In Meinhard v. Salmon, 164 N.E. 545 (N.Y. 1928), the court held that business partners have a fiduciary duty in the course of activities associated with their partnership. 
consequently they do not have a full fiduciary duty. Brokers' duties are established in the Securities Exchange Act of 1934, which does not set a fiduciary standard.

One implication is that many workers have much greater effective regulatory protection than retirees. Employer 401(k) plans and other definedcontribution plans are regulated by ERISA, which, as noted, imposes a strong fiduciary duty on the employer. IRAs, in contrast, have a much lower level of protection, since the representatives of the securities broker-dealer firms that manage these accounts are not full-fledged fiduciaries. Thus, when a retiree rolls money over from her $401(\mathrm{k})$ account to an IRA, as happens with the overwhelming majority of $401(\mathrm{k})$ assets, her savings lose the fiduciary protection she enjoyed as an employee. Of course, nobody forces retirees to make these rollovers, but the financial services industry has a strong incentive to encourage them, since fees are higher in practice outside of $401(\mathrm{k})$ accounts. ${ }^{26}$

Mandating fiduciary responsibilities, even weak ones, on the sellers of financial services would give them a stronger incentive to design and market products that meet high standards. But it might also generate new administrative and compliance costs and slow financial innovation. If these inefficiencies were to prove considerable, an alternative would be to mandate fiduciary duties only in certain circumstances, for example when the buyer is above some age threshold. Other intermediate solutions would be to impose on IRA asset managers the same fiduciary duties as 401(k) plan sponsors, or to strongly discourage rollovers from $401(\mathrm{k}) \mathrm{s}$ to IRAs.

\section{V.F. Mandatory Advance Directives}

One way to address directly the impact of cognitive decline on financial decisionmaking would be to require older adults to put in place a financial advance directive before reaching a certain age. Such mandatory advance directives could take many forms. For instance, older adults might be required to create a durable power of attorney, so that somebody would be able to manage their financial affairs in the event of their incapacity. ${ }^{27}$ Alternatively, older adults might be required to create a streamlined version of a revocable living trust. Such trusts enable individuals to pass management of their assets to a fiduciary in the event of the principal's incapacity.

26. In principle, investors could purchase low-fee products in their IRAs. In practice, they overwhelmingly fail to do so.

27. Alternatively, this could be a springing power of attorney, which takes effect only in the event of their incapacity. 
Entirely new legal protections might also be created. For example, a fiduciary could be appointed to approve all "significant financial transactions" involving the principal's funds after the principal reaches a designated age. A significant financial transaction might be defined as any transaction representing more than a certain share (which could decrease with the principal's age) of the principal's net worth. The principal would preset this threshold for fiduciary approval at the time the advance directive is created. To make the process easier, a default schedule could be established, for example, beginning at 50 percent of net worth at age 75 and falling as the principal ages. If a seller then enters into a financial transaction with the principal without formal approval from the principal's fiduciary, and it is subsequently determined that the transaction exceeded the relevant threshold, the transaction could be nullified. In addition, the directive would stipulate who will judge the principal's mental capacity and how the principal's assets would be administered in the event the principal is judged no longer mentally competent. Finally, the details of the directive (including the choice of fiduciary) could be changed at any time if the principal can demonstrate mental competency.

As an alternative to these fiduciary-based models, the principal could also be allowed to place her assets in a safe harbor (see next subsection) that eliminates the need for a fiduciary. This option would appeal to families that do not have substantial assets and would therefore not find the appointment of a fiduciary to be cost-effective.

Mandating advance directives would pose several problems. First, it might be perceived by some older adults as an unfair restriction targeted against them. Second, the imposition of a fiduciary would create transactions costs. Third, any attempt to define a safe harbor would be politically contentious and would doubtless give rise to a great deal of lobbying. An independent agency would probably be needed to partly insulate the safe harbor regulations from political pressure.

\section{V.G. Protected Assets: A Life-Cycle Safe Harbor}

A portion of a retiree's financial assets could be protected in a mandatory safe harbor, with four basic features: ${ }^{28}$

28. We use the term "safe harbor" with two complementary meanings in mind. First, the standard legal usage is relevant, since the firms managing these safe harbor assets and following the relevant regulatory guidelines would be protected from lawsuits. Second, the investors themselves would be protected from exploitation by those same regulatory guidelines. 
-First, an asset base would be identified. This would probably include all forms of savings that have benefited from federal tax relief, such as qualified defined-contribution plans and all types of IRAs.

- Second, when the principal reaches a specified age, a portion of this asset base would be irrevocably placed in a safe harbor account, that is, one that is permitted to hold only certain types of assets. For example, at age $591 / 2,29$ every account in the asset base could be required to distribute 50 percent of the balance into such an account. In principle, the safe harbor accounts could be managed by the same company that managed the original accounts, obviating the need for direct government involvement.

- Third, the investor would choose from among a limited range of highly regulated, low-cost investment options for the assets within the safe harbor. These options might include a fixed annuity, a variable annuity, a bond mutual fund, and a life-cycle mutual fund (which would contain a diversified portfolio of stocks and bonds).

-Finally, the account would have a minimum and a maximum rate of drawdown. The minimum rate could be set according to current rules on required minimum distributions from tax-deferred accounts. ${ }^{30}$ The maximum rate, which would rise with age, would be set to preserve the assets so that they provide a nontrivial stream of retirement income until the principal's death.

Such a system would provide four benefits. First, a substantial fraction of the retiree's assets would be protected from high fees, from suboptimal investments, and from fraud. Second, the pooling of the assets in the safe harbor into a small number of investment vehicles would achieve scale economies and might mitigate adverse selection problems in the case of annuitized assets. Third, retirees would be at least partly constrained from spending down their assets prematurely. Fourth, society at large would benefit because household savings would cover a larger fraction of longterm care and other medical expenses. ${ }^{31}$

At first glance, the proposal just described may seem novel. But it is actually just a generalization of mandatory annuitization schemes that are

29. This transfer to the safe harbor would occur just before early withdrawal penalties are terminated at age $59 \frac{1}{2}$. The transfer would incur no penalty, since the assets would remain in the retirement savings system. Individuals who try to avoid the transfer to the safe harbor by prematurely withdrawing assets from their tax-deferred accounts would face a 10 percent penalty.

30. Note that Roth IRAs are not currently covered by lifetime RMDs.

31. Under the proposal made here, fewer assets could be transferred during one's lifetime to one's children, and so those assets would be available to cover some of the long-term care costs that would otherwise be borne by Medicaid. 
already commonplace in Europe, Latin America, and Asia (Antolin, Pugh, and Stewart 2008).

The proposal has two potential disadvantages. First, it would meaningfully restrict individual choice by requiring households to invest some of their retirement savings in a limited menu of assets and by constraining their consumption path. Second, it would create the potential for political manipulation by empowering a regulator to select and monitor the asset menu. As we argued above, an independent agency might be needed to insulate the regulator.

\section{V.H. Default Regulatory Approval: The Dietary Supplements Model}

Up to this point we have focused on interventions that primarily target the individual investor. Regulations could instead target the financial products themselves. One such regime would mimic the regulatory model currently used for nutritional supplements: new financial products would be allowed in the market without specific formal approval in advance but would be monitored for adverse effects. The other, discussed in the next subsection, would require that new financial products obtain explicit regulatory approval before being marketed.

The Dietary Supplement Health and Education Act of 1994 established a novel regulatory framework for nutritional supplements. ${ }^{32}$ Unlike food additives and drugs, dietary supplements do not need to be approved by the Food and Drug Administration (FDA) before being brought to market, nor are they subject to formal requirements for ex ante safety and efficacy testing. Instead, the supplement manufacturer does its own due diligence, applying safety and marketing rules that have been established by the FDA. The manufacturer is responsible for ensuring that its supplement adheres to these established regulatory standards for safety and truthful labeling. The manufacturer does not even need to register the supplement with the FDA. The FDA is responsible for taking action against any unsafe supplements that it identifies in the marketplace. Under this system, dietary supplements thus have default regulatory approval.

Financial products could be regulated in much the same way. Safety and quality standards would be established by the relevant regulator, typically the SEC, and financial services firms would then evaluate their own products to determine whether they comply with the standards. Such a sys-

32. Dietary supplements, also known as nutritional supplements, include vitamins, minerals, botanical and herbal remedies, fiber, fatty acids, amino acids, and other substances believed to improve health. The current regulatory regime is described on the FDA's webpage "Dietary Supplements" (www.fda.gov/Food/DietarySupplements/default.htm). 
tem would avoid the need for rigorous and time-consuming regulatory review for each new product and would encourage innovation.

Naturally, this system would work well only if the regulator could successfully identify socially optimal ex ante standards. This might be difficult. Such standards would need to be based both on the characteristics of the product being marketed and on those of the buyer. For instance, products that might be appropriate for young investors (such as equity-based leveraged ETFs) might be deemed inappropriate for an 85-year-old retiree.

\section{V.I. Mandatory Explicit Regulatory Approval}

The final regulatory approach draws on the model currently used by the FDA for drugs (as opposed to dietary supplements). New drugs must undergo extensive, documented testing for safety and efficacy and may not be sold until formally approved by the FDA. This testing takes years and is generally extremely costly to the pharmaceutical firm developing the drug. Once approved, new drugs may be sold only by prescription until the FDA formally approves them, in a separate process, for overthe-counter sales.

Financial products could be made subject to such an ex ante review process and tested in small-scale trials much as drugs are today. For example, a new credit product could be offered (at regular cost) to 10,000 clients during a trial period. Their behavior could be studied anonymously, and they could be anonymously surveyed about their experiences. The survey could be designed by the financial regulator or outsourced to a third party monitored by the regulator and could ask such questions as the following:

-Do you feel that this product generates value that exceeds the fees you are paying for it?

-What are the fees on this product? ("Don't know" would be an option here.)

—Would you recommend this product to any of your friends?

- In your view, should this product be approved for sale?

Naturally, a product could be approved even if a sizable minority of customers did not understand it or did not like it. However, if a large enough fraction expressed reservations about its value or did not understand its costs, this would be grounds for further study and possibly rejection. The regulator would try to judge the aggregate benefits and harms generated by the product, recognizing the possibility that modest harm to many consumers might be offset by large gains to a small number.

Such testing would be socially costly. It would delay the release of new products, increase costs for financial services firms, and discourage 
innovation. But it could also prevent the marketing of socially undesirable products. The net social benefit is not easy to evaluate.

Finally, note that testing could occur after a product has been released. For example, the regulator could be given the authority to compel a product's developer to perform the analysis described above on products that have been found after their introduction to be potentially problematic. Such ex post selection for testing might be superior to ex ante testing of all new products. Financial service firms would have an incentive to design products that do not attract the potentially costly scrutiny of the regulator.

\section{Seven Open Questions for Future Research}

This paper has undertaken three main tasks. First, we reported evidence that older adults experience substantial declines in cognitive function over time. Then, we reported evidence that economic behavior and economic mistakes show strong age-based patterns in the cross section, even among a population of individuals who are screened to be prime borrowers. Finally, we discussed nine potential policy responses. We emphasized that we are agnostic about what regulatory interventions (if any) should be adopted. We do not think that the jury is in on many different dimensions of the problem. Economic behavior among older adults is still poorly understood. Moreover, even if older adults are making substantial financial mistakes, it is not clear what a well-intentioned policymaker should do about it. Much more research is needed-including field experiments that study different regulatory regimes-before the best solutions can be identified. ${ }^{33}$ In this concluding section we identify seven open questions that we hope academic researchers and policymakers will consider as they wrestle with these problems in the future.

First, how widespread and important are losses due to poor financial decisionmaking? What fraction of aggregate wealth, and of the wealth of older adults, is lost because of poor choices? What are the utility costs?

In our analysis of economic behavior, we were able to study only a set of decisions with relatively moderate costs, such as credit card fees. We believe that these costs are just the tip of the iceberg. We studied these particular transactions because the data are of good quality, but the bulk of the mistakes that are probably being made lie elsewhere. Older adults make many decisions with potentially enormous costs. Should I refinance my

33. The law and economics literature also studies those issues. See, for example, BarGill (2009) and Marotta-Wurgler (2007). 
home and draw down some of my equity? Should I buy a complicated (high-fee) annuity? Should I cash out my current annuity (paying a surrender charge) so I can buy a better one? Should I invest a substantial fraction of my wealth in a high-return CD offered by a broker calling from an offshore bank? Should I invest a substantial fraction in a structured finance product that has a high return and that I am assured is completely safe? Should I participate in a real estate investment pool with a minimum investment of $\$ 100,000$ ?

Measuring and aggregating these costs is an important research program. To get a sense of how they might add up, consider a few quantitative examples. Wealth dissipation in the annuity market is estimated at about 6 percent of the value of each annuity purchased, for a total of $\$ 16$ billion in $2008 .{ }^{34}$ Korniotos and Kumar (forthcoming-a) estimate that older investors with accounts at a discount brokerage earn 3 percent less in risk-adjusted equity returns than middle-aged clients of the same broker. Even if the true aggregate figure is just 0.3 percent of total financial assets held by older adults, this would translate into $\$ 40$ billion of underperformance per year. ${ }^{35}$

It is unclear whether these amounts are transfers between parties or deadweight losses. As an order of magnitude for the stakes, Kenneth French (2008) estimates total fees paid in active financial management to be about 0.7 percent of the market value of equity per year, which is equivalent to about 0.7 percent of GDP. This may mostly be a deadweight loss, because the active traders (as well as the marketing experts who advertise these funds) could be productively engaged in other activities. The active traders are engaged primarily in trying (usually unsuccessfully) to transfer wealth to their clients from other people. The transfers themselves are not a deadweight loss, but the time spent attempting to achieve those transfers is. Physics Ph.D.s might be more usefully employed in labs rather than at hedge funds.

Second, what demographic characteristics predict poor financial decisionmaking? In this paper we have used only data on age, but clearly other demographic measures (years of education, field of education) would be

34. See LIMRA (formerly the Life Insurance and Market Research Association), "Annuity Sales Estimates, 1999-2008" (www.limra.com/PDFs/newscenter/databank/Annuity Estimates99_08.pdf), for the volume of the annuities market. A typical commission on the sale of an annuity ranges from 6 to 12 percent of the face value of the contract. Annuities with small or zero commissions exist but represent a small part of the market.

35. The Federal Reserve estimates that households own financial assets worth about $\$ 40$ trillion, excluding deposits (Flow of Funds, table B.100). The Survey of Consumer Finances implies that 34 percent of that wealth is owned by households with a head age 65 or older. 
helpful. One would also like to know whether cognitive tests are predictive of poor financial decisionmaking, and if so, what kinds of tests (knowledge-based, logic-based, or others). Is it possible to inexpensively and accurately measure an individual's current level of cognitive function or to predict future changes?

Third, to what extent do people anticipate their own cognitive decline or recognize it when it happens? And if they do, are they able to delegate their financial affairs or protect themselves in other ways (for example, by politely ending the conversation when they are solicited over the phone to attend a free lunch or investment seminar)? We do not know how malleable older adults really are. One often hears anecdotes about aging widows who vaguely realize that they are experiencing some cognitive decline but still fall prey to sophisticated and sociable brokers. Are these stories representative? Or are the vast majority of older adults able to protect themselves because they recognize their own vulnerability?

Fourth, does financial education help? Is it cost-effective? Is it relevant in a changing financial environment? As discussed above, the evidence on the impact of financial education is mixed and not particularly encouraging. For example, Agarwal and others (2009) find that mortgage counseling does not help consumers choose lower-risk mortgage products.

Fifth, do third parties help? Who should be empowered to serve as an external adviser or decisionmaker? A family member? a friend? an independent trustee ${ }^{36}$ Family members sometimes make problematic trustees-as illustrated in cases ranging from King Lear to Brooke Astor-but how prevalent are such problems? What is the evidence on the effectiveness of different types of trustee? How does the market for fiduciaries operate?

Sixth, what is the market response to this situation, and does it help or hurt? There are theoretical reasons to worry that the market mechanism might be inefficient in the market for advice. Advice markets suffer by definition from information asymmetries between providers and recipients (see the survey in Dulleck and Kerschbamer 2006). In markets with inattentive consumers and shrouded attributes (Gabaix and Laibson 2006), perverse situations with high fees can persist as bona fide economic equilibria when there are enough naive consumers and the only profitable business model is to offer a product with low base prices and high "surprise" fees. How important empirically are these perverse market equilibria? Are professional fiduciaries trustworthy or not? There is much anecdotal evi-

36. See Li (2009) for empirical evidence on financial advice by family members. 
dence of problems, for example of outrageously high fees, but a systematic quantification is needed.

Finally, what is the appropriate regulatory response? If the market for third-party advice and fiduciary services functioned well, the market equilibrium would have three phases. Early in life, each individual would write a plan for his or her future consumption and investment, contingent on major events (including cognitive decline). Then, cognitive testing and observation would monitor the individual for the onset of significant cognitive decline. Finally, once this prespecified threshold has been crossed, the original contingent plan would be enforced by a fiduciary, or the individual's assets would be placed in a financial instrument with a statecontingent payout scheme. Indeed, the market already provides financial products with this feature: for example, annuities eliminate complex asset decumulation decisions. More sophisticated institutions will be designed. However, for all of the reasons reviewed in this paper, the unregulated market solution may not work well. Government intervention is probably desirable, but the ideal form of that intervention remains unclear. More empirical analysis and field experiments are needed to identify the regulatory response that best balances the marginal costs against the potential benefits.

\section{APPENDIX}

\section{Data Description}

\section{Eureka Moments}

We use a proprietary panel dataset with data from several large financial institutions, later acquired by a single financial institution that made balance transfer offers nationally. The offers were not made conditional on closing the old credit card account. The dataset contains information on 14,798 individuals who accepted such balance transfer offers over the period January 2000 through December 2002. The bulk of the data consists of the main billing information listed on each account's monthly statement, including total payment, spending, credit limit, balance, debt, purchase APRs, cash advance APRs, and fees paid. We also observe the amounts of all balance transfers, the start and end dates of the balance transfer teaser rate offer, and the initial teaser APR on the balance transfer. At a quarterly frequency, we observe each customer's credit bureau rating (FICO) score and a proprietary (internal) credit "behavior" score. We have 
credit bureau data about the number of other credit cards held by each accountholder, total credit card balances, and mortgage balances. We also have data on the age, sex, and income of the accountholder, collected when the account was opened. In this sample, borrowers did not pay a fee for balance transfers.

\section{Home Equity Loans and Lines of Credit}

We use a proprietary panel dataset constructed from records from a national financial institution that has issued home equity loans and home equity lines of credit. This lender has not specialized in subprime loans or other market segments. Between March and December 2002, the lender offered a menu of standardized contracts for home equity credit. ${ }^{37}$ Consumers chose either a loan or a credit line, either a first or a second lien, and an incremental loan amount, which, given an estimate of the property's value, resulted in an LTV ratio of less than 80 percent, between 80 and 90 percent, or between 90 and 100 percent. Thus, in effect, the lender offered 12 different contract choices. ${ }^{38}$ We ran separate regressions for home equity loans and lines of credit, conditioning in each case on not having a first mortgage and on the LTV ratio categories described above; hence, we control for contract type. All loans have the same five-year maturity. For 75,000 such contracts, we observe the contract terms, demographic information about the borrower (age, years at current job, and home tenure), financial information (income and debt-to-income ratio), and risk characteristics (FICO score and LTV). ${ }^{39}$ We also observe the borrower's estimate of the property's value and the loan amount requested.

37. Other interest rates in the economy varied considerably during this time period. One might therefore ask whether the age results we report are an artifact of borrowers of different ages happening to disproportionately borrow earlier or later in the sample. We observe no pattern in the distribution by month of borrowing by age over the sample. In alternative versions of the regressions including dummy variables for the month of loan origination, we obtain nearly identical results.

38. We focus on APRs across contracts for four reasons. First, the contracts in the dataset do not differ in points (origination fees as a percent of the loan) charged or in other charges to the borrower. Second, we verified that even conditioning on contract choice, some borrowers pay higher APRs than others. Third, we controlled for borrower risk characteristics. Fourth, we show in the paper that the residual variation in APRs is explained by the propensity to make an identifiable mistake in the loan acquisition process.

39. We do not have internal behavior scores (a supplementary credit risk score) for these borrowers. Such scores are performance based and are thus not available at loan origination. 


\section{Auto Loans}

We use a proprietary dataset of auto loans originated at several large financial institutions that were later acquired by another institution. The dataset comprises observations on 6,996 loans originated for the purchase of new and used automobiles. Observed loan characteristics include the automobile's value and age, the loan amount and LTV, the monthly payment, the contract rate, and the date of origination. Observed borrower characteristics include credit score, monthly disposable income, and age.

\section{Mortgages}

We use a proprietary dataset from a large financial institution that originates first mortgages in Argentina. Using data from another country provides suggestive evidence about the international applicability of our findings. The dataset covers 4,867 owner-occupied, fixed-rate, first mortgage loans originated between June 1998 and March 2000 and observed through March 2004. We observe the original loan amount, the LTV and appraised home value at origination, and the APR. We also observe borrower financial characteristics (including income, second income, years on the job, and wealth measures such as second home ownership, car ownership, and car value), risk characteristics (the borrower's Veraz score-a credit score similar to the U.S. FICO score-and mortgage payments as a percentage of after-tax income), and demographic characteristics (age, sex, and marital status).

\section{Small Business Credit Cards}

We use a proprietary dataset of small business credit card accounts originated at several large institutions that issued such cards nationally. The institutions were later acquired by a single institution. The panel dataset covers 11,254 accounts originated between May 2000 and May 2002. Most of the businesses are very small, are owned by a single family, and have no public financial records. The dataset has all the information collected at the time of account origination, including the business owner's self-reported personal income, the number of years the business has been in operation, and the age of the business owner. We also observe the quarterly credit bureau score of the business owner. 


\section{Credit Card Fees}

We use a proprietary panel dataset from several large financial institutions that offered credit cards nationally; these institutions were later acquired by a larger financial institution. The dataset contains a representative random sample of about 128,000 credit card accounts followed monthly over a 36-month period from January 2002 through December $2004 .{ }^{40}$ The bulk of the data consists of the main billing information listed on each account's monthly statement, including total payments, spending, credit limit, balance, debt, APRs on purchases and cash advances, and fees paid. At a quarterly frequency, we observe each customer's credit bureau (FICO) score and a proprietary (internal) credit "behavior" score. For each cardholder we have credit bureau data on the number of other credit cards held, total credit card balances, and mortgage balances. We also have data on the age, sex, and income of the cardholder, collected when the account was opened. Further details, including summary statistics, are available in the online appendix.

ACKNOWLEDG M ENTS Xavier Gabaix and David Laibson acknowledge support from the National Science Foundation (DMS-0527518). Laibson acknowledges financial support from the National Institute on Aging (R01AG-021650, R01-AG-1665, P30-AG-012810). The views expressed in this paper are those of the authors and do not represent the policies or positions of the Board of Governors of the Federal Reserve System or the Federal Reserve Bank of Chicago. For their helpful comments we thank the editors and Marco Basetto, John Beshears, Stephane Bonhomme, James Choi, David Cutler, Giovanni Dell'Ariccia, Ray Fair, Luigi Guiso, Gur Huberman, Erik Hurst, Brigitte Madrian, Ulrike Malmendier, Karen Pence, Mitchell Petersen, Richard Rosen, Timothy Salthouse, Fiona Scott-Morton, Jesse Shapiro, William Sharpe, Paolo Sodini, Nicholas Souleles, Richard Suzman, Jonathan Zinman, and participants at various conferences and seminars. We thank Jacqueline Barrett and Kyle Chauvin for excellent research assistance.

40. The credit cards do not have annual fees and do not differ in terms of rewards points or other benefits. 


\section{References}

Agarwal, Sumit. 2007. “The Impact of Homeowners' Housing Wealth Misestimation on Consumption and Saving Decisions." Real Estate Economics 35, no. 2: 135-54.

Agarwal, Sumit, Souphala Chomsisengphet, Chunlin Liu, and Nicholas S. Souleles. 2006. "Do Consumers Choose the Right Credit Contracts?" Working paper. Federal Reserve Bank of Chicago.

Agarwal, Sumit, John C. Driscoll, Xavier Gabaix, and David Laibson. 2008. "Learning in the Credit Card Market." Working Paper no. 13822. Cambridge, Mass.: National Bureau of Economic Research (February).

Agarwal, Sumit, Gene Amromin, Itzhak Ben-David, Souphala Chomsisengphet, and Douglas D. Evanoff. 2009. "Do Financial Counseling Mandates Improve Mortgage Choice and Performance? Evidence for a Legislative Experiment." Working paper. Federal Reserve Bank of Chicago.

Aguiar, Mark, and Erik Hurst. 2007. "Life-cycle Prices and Production." American Economic Review 97, no. 5: 1533-59.

Alesina, Alberto, and Annamaria Lusardi. 2006. "Driving Your Financial Investment? Perhaps a License Is Needed." Vox of Dartmouth 25, no. 2 (July 24).

Antolin, P., C. Pugh, and F. Stewart. 2008. "Forms of Benefit Payment at Retirement." OECD Working Papers on Insurance and Private Pensions no. 26. Paris: OECD Publishing.

Ausubel, Lawrence M. 1991. "The Failure of Competition in the Credit Card Market." American Economic Review 81, no. 1: 50-81.

Bar-Gill, Oren. 2009. "The Law, Economics and Psychology of Subprime Mortgage Contracts." Cornell Law Review 94, no. 5: 1073-1115.

Ben-David, Itzhak. 2008. "Manipulation of Collateral Values by Borrowers and Intermediaries." Working paper. University of Chicago Graduate School of Business.

Benjamin, Daniel J., Sebastian A. Brown, and Jesse M. Shapiro. 2006. "Who Is 'Behavioral'? Cognitive Ability and Anomalous Preferences." Working paper. University of Chicago and Harvard University.

Beshears, John, James J. Choi, David Laibson, and Brigitte C. Madrian. 2008. "The Importance of Default Options for Retirement Saving Outcomes: Evidence from the USA." In Lessons from Pension Reform in the Americas, edited by Stephen J. Kay and Tapen Sinha. Oxford University Press.

_ 2009a. "How Does Simplified Disclosure Affect Individuals' Mutual Fund Choices?" Working Paper no. 09-05. Yale International Center for Finance (March).

. 2009b. "The Limits of Defaults." Harvard University.

Bucks, Brian, and Karen Pence. 2006. "Do Homeowners Know Their House Values and Mortgage Terms?" Finance and Economics Discussion Paper Series. Washington: Federal Reserve Board.

Campbell, John Y. 2006. "Household Finance." Journal of Finance 61, no. 4 (August): 1553-1604. 
Carstensen, Laura L. 2006. "The Influence of a Sense of Time on Human Development." Science 312, no. 5782 (June): 1913-15.

Cattell, Raymond B., ed. 1987. Intelligence: Its Structure, Growth and Action. New York: Elsevier.

Charles, Kerwin Kofi, Erik Hurst, and Melvin Stephens, Jr. 2008. "Rates for Vehicle Loans: Race and Loan Source." American Economic Review, Papers and Proceedings 98, no. 2: 315-20.

Choi-Allum, Lona. 2009. "Protecting Older Investors: 2009 Free Lunch Seminar Report." Washington: AARP.

Choi, James J., David Laibson, Brigitte C. Madrian, and Andrew Metrick. 2002. "Defined Contribution Pensions: Plan Rules, Participant Choices, and the Path of Least Resistance." Tax Policy and the Economy 16: 67-114.

Choi, James J., David Laibson, and Brigitte C. Madrian. 2005. "Are Empowerment and Education Enough? Underdiversification in 401(k) Plans." BPEA, no. 2: 151-98.

2007. "\$100 Bills on the Sidewalk: Suboptimal Investment in 401(k) Plans." Working Paper no. 11554 (revised). Cambridge, Mass.: National Bureau of Economic Research (December).

DellaVigna, Stefano, and Ulrike Malmendier. 2004. "Contract Design and SelfControl: Theory and Evidence." Quarterly Journal of Economics 119, no. 2: 353-402.

Denburg, N., D. Tranel, and A. Bechara. 2005. "The Ability to Decide Advantageously Declines Prematurely in Some Normal Older Persons." Neuropsychologia 43, no. 7: 1099-1106.

Dulleck, Uwe, and Rudolf Kerschbamer. 2006. "On Doctors, Mechanics, and Computer Specialists: The Economics of Credence Goods." Journal of Economic Literature 44, no. 1: 5-42.

Ferri, Cleusa P., Martin Prince, Carol Brayne, Henry Brodaty, Laura Fratiglioni, Mary Ganguli, Kathleen Hall, Kazuo Hasegawa, Hugh Hendrie, Yueqin Huang, Anthony Jorm, Colin Mathers, Paulo R. Menezes, Elizabeth Rimmer, and Marcia Scazufca. 2005. "Global Prevalence of Dementia: A Delphi Consensus Study." The Lancet 366(9503) (December): 2112-17.

Flynn, James R. 1984. "The Mean IQ of Americans: Massive Gains 1932 to 1978." Psychological Bulletin 95, no. 1 (January): 29-51.

Fratiglioni, L., D. De Ronchi, and H. Agüero Torres. 1999. "Worldwide Prevalence and Incidence of Dementia." Drugs \& Aging 15, no. 5 (November): 365-75.

Frederick, Shane. 2005. "Cognitive Reflection and Decision Making." Journal of Economic Perspectives 19, no. 4 (Fall): 25-42.

French, Kenneth R. 2008. "The Cost of Active Investing." Journal of Finance 63, no. 4: 1537-73.

Gabaix, Xavier, and David Laibson. 2006. "Shrouded Attributes, Consumer Myopia, and Information Suppression in Competitive Markets." Quarterly Journal of Economics 121, no. 2 (May): 505-40. 
Galenson, David W. 2006. Old Masters and Young Geniuses: The Two Life Cycles of Artistic Activity. Princeton University Press.

Gourinchas, Pierre-Olivier, and Jonathan A. Parker. 2002. "Consumption over the Life Cycle." Econometrica 70, no. 1 (January): 47-89.

Graham, John R., Campbell R. Harvey, and Manju Puri. 2008. "Managerial Attitudes and Corporate Actions." Working paper. Fuqua School of Business, Duke University.

Heidhues, Paul, and Botond Kőszegi. 2009. "Exploiting Naivete about SelfControl in the Credit Market.” Working paper. University of California, Berkeley, and University of Bonn.

Jones, Benjamin F. 2005. "Age and Great Invention.” Working Paper no. 11359. Cambridge, Mass.: National Bureau of Economic Research (May).

—. 2008. "Superior Information or a Psychological Bias? A Unified Framework with Cognitive Abilities Resolves Three Puzzles." Working paper. Federal Reserve Board and University of Texas (www.aeaweb.org/annual_ mtg_papers/2009/).

Korniotis, George M., and Alok Kumar. Forthcoming-a. "Do Older Investors Make Better Investment Decisions?" Review of Economics and Statistics.

- Forthcoming-b. "Cognitive Abilities, Investor Sophistication, and Investment Decisions." Chapter 30 in Behavioral Finance, edited by H. Kent Baker and John R. Nofsinger. John Wiley \& Sons.

Langa, Kenneth M., Brenda L. Plassman, Robert B. Wallace, A. Regula Herzog, Steven G. Heeringa, Mary Beth Ofstedal, James R. Burke, Gwenith G. Fisher, Nancy H. Fultz, Michael D. Hurd, Guy G. Potter, Willard L. Rodgers, David C. Steffens, David R. Weir, and Robert J. Willis. 2005. "The Aging, Demographics, and Memory Study: Study Design and Methods." Neuroepidemiology 25, no. 4: 181-91.

Li, Geng. 2009. "Information Sharing and Stock Market Participation: Evidence from Extended Families." Working paper. Washington: Federal Reserve Board.

Lusardi, Annamaria, and Olivia S. Mitchell. 2006. "Financial Literacy and Planning: Implications for Retirement Wellbeing." DNB Working Paper 078. Amsterdam: De Nederlandsche Bank.

. 2007. "Financial Literacy and Retirement Preparedness: Evidence and Implications for Financial Education.” Business Economics 42, no. 1 (January): 35-44.

Madrian, Brigitte C., and Dennis F. Shea. 2001a. "The Power of Suggestion: Inertia in 401(k) Participation and Savings Behavior." Quarterly Journal of Economics 116, no. 4 (November): 1149-87.

2001b. "Preaching to the Converted and Converting Those Taught: Financial Education in the Workplace." Working paper. University of Chicago.

Malmendier, Ulrike, and Stefan Nagel. 2007. "Depression Babies: Do Macroeconomic Experiences Affect Risk-Taking?" Working paper. University of California, Berkeley. 
Malmendier, Ulrike, and Devin Shanthikumar. 2007. "Are Small Investors Naive about Incentives?” Journal of Financial Economics 85, no. 2 (August): 457-89.

Marotta-Wurgler, Florencia. 2007. "What's in a Standard Form Contract? An Empirical Analysis of Software License Agreements." Journal of Empirical Legal Studies 4, no. 4: 677-713.

Mather, Mara, and Laura L. Carstensen. 2005. "Aging and Motivated Cognition: The Positivity Effect in Attention and Memory." Trends in Cognitive Sciences 9, no. 10: 496-502.

McArdle, John J., James P. Smith, and Robert Willis. Forthcoming. "Cognition and Economic Outcomes in the Health and Retirement Survey." In Explorations in the Economics of Aging, edited by David Wise. Cambridge, Mass.: National Bureau of Economic Research.

Mottola, Gary R., and Stephen P. Utkus. 2007. "Lump Sum or Annuity? An Analysis of Choice in DB Pension Payouts." Valley Forge, Pa.: Vanguard Center for Retirement Research (November).

Mullainathan, Sendhil, and Andrei Shleifer. 2005. "The Market for News." American Economic Review 95, no. 4: 1031-53.

Murphy, Kevin M., and Finis Welch. 1990. "Empirical Age-Earnings Profiles." Journal of Labor Economics 8, no. 2: 202-29.

Ofstedal, Mary Beth, Gwenith G. Fisher, and A. Regula Herzog. 2005. "Documentation of Cognitive Functioning Measures in the Health and Retirement Study." HRS Documentation Report DR-006. University of Michigan (March).

Park, Denise, and Norbert Schwarz, eds. 2000. Cognitive Aging: A Primer. Psychology Press.

Plassman, Brenda L., Kenneth M. Langa, Gwenith G. Fisher, Steven G. Heeringa, David R. Weir, Mary Beth Ofstedal, James R. Burke, Michael D. Hurd, Guy G. Potter, Willard L. Rodgers, David C. Steffens, John J. McArdle, Robert J. Willis, and Robert B. Wallace. 2008. "Prevalence of Cognitive Impairment without Dementia in the United States." Annals of Internal Medicine 148, no. 6 (March 18): 427-34.

Poterba, James, Steven Venti, and David A. Wise. 2008. "New Estimates of the Future Path of 401(k) Assets." Tax Policy and the Economy 22: 43-80.

Salthouse, Timothy A. 2005. "Effects of Aging on Reasoning." In The Cambridge Handbook of Thinking and Reasoning. Cambridge University Press.

- Forthcoming. "Executive Functioning." In Cognitive Aging: A Primer, 2nd ed., edited by D. C. Park and N. Schwarz. London: Psychology Press.

Salthouse, Timothy A., David H. Schroeder, and Emilio Ferrer. 2004. "Estimating Retest Effects in Longitudinal Assessments of Cognitive Functioning in Adults between 18 and 60 Years of Age." Developmental Psychology 40, no. 5: 813-22.

Scholnick, Barry, Nadia Massoud, and Anthony Saunders. 2008. "The Impact of Wealth on Inattention: Evidence from Credit Card Repayments?" Working Paper 2008-10. Arlington, Va.: FDIC Center for Financial Research.

Scott Morton, Fiona, Florian Zettelmeyer, and Jorge Silva-Risso. 2003. "Consumer Information and Discrimination: Does the Internet Affect the Pricing of New 
Cars to Women and Minorities?" Quantitative Marketing and Economics 1, no. 1: 65-92.

Shue, Kelly, and Erzo F. P. Luttmer. 2009. "Who Misvotes? The Effect of Differential Cognition Costs on Election Outcomes." American Economic Journal: Economic Policy 1, no.1: 229-57.

Shui, Haiyan, and Lawrence M. Ausubel. 2005. “Time Inconsistency in the Credit Card Market." Working paper. University of Maryland.

Simonton, D. K. 1988. "Age and Outstanding Achievement: What Do We Know after a Century of Research?" Psychological Bulletin 104, no. 2: 251-67.

Spiegler, Ran. 2006. “The Market for Quacks.” Review of Economic Studies 73, no. 4: 1113-31.

Stango, Victor, and Jonathan Zinman. 2009. "Exponential Growth Bias and Household Finance." Journal of Finance (forthcoming).

Thaler, Richard H., and Shlomo Benartzi. 2004. "Save More Tomorrow: Using Behavioral Economics to Increase Employee Saving." Journal of Political Economy 112, no. 1, part 2: S164-87.

Thaler, Richard H., and Cass R. Sunstein. 2003. "Libertarian Paternalism." American Economic Review, Papers and Proceedings 93, no. 2 (May): 175-79.

2008. Nudge: Improving Decisions about Health, Wealth, and Happiness. Yale University Press.

Weinberg, Bruce A., and David W. Galenson. 2005. "Creative Careers: The Life Cycle of Nobel Laureates in Economics." Working Paper no. 11799. Cambridge, Mass.: National Bureau of Economic Research.

Willis, Robert J. 2007. "Cognitive Economics and Human Capital.” Presidential Address to the Society of Labor Economists, Chicago, May.

Zinman, Jonathan. 2007. "Where Is the Missing Credit Card Debt? Clues and Implications.” Discussion Paper 07-11. Federal Reserve Bank of Philadelphia. 


\section{Comments and Discussion}

\section{COMMENT BY}

GIOVANNI DELL'ARICCIA ${ }^{1}$ Those whom the gods love die young. Yet we grow old always learning new and interesting things. This paper by Sumit Agarwal, John Driscoll, Xavier Gabaix, and David Laibson does some justice to both these statements. And like all good economic papers, it identifies a trade-off. You can be young and foolish: at the peak of your cognitive abilities, but also very ignorant. Or you can be old and a bit slow: having accumulated a lot of experience, but with depleted analytical capital. In the middle is an "age of reason" at which you have learned enough and are still able to exploit your experience and to process new information. The paper argues that these dynamics are reflected in a life-cycle pattern of financial mistakes and performance. Its findings are relevant from a policy perspective, especially given the continuing aging of the population in most advanced economies. But I suspect they will be intriguing (and a bit scary) even for those who are not particularly interested in economic policymaking or behavioral finance.

I will structure my comments as follows. First, I will attempt to provide alternative explanations for the main empirical patterns identified in the paper. The authors present relatively convincing evidence linking the lifecycle pattern of high interest rates paid and other financial mistakes to progressive cognitive decline. However, it is worth exploring whether a framework that does not rely on bounded rationality can produce a similar pattern. In particular, I will focus on whether more standard, industrial organization-based stories can deliver similar results. Second, I will delve into how such a framework can explain the paper's two most convincing

1. The views expressed in this paper are those of the author and do not necessarily represent those of the International Monetary Fund. 
pieces of empirical evidence: the "eureka moments" on credit card balance transfers and the "rate-changing mistakes" on home equity loan applications. Finally, I will briefly discuss the paper's policy implications.

The paper hypothesizes that net cognitive performance is hump-shaped with respect to age. This results from assuming that performance is determined by the sum of analytical capital, which declines linearly with age, and experiential capital, which rises with age but exhibits diminishing returns. The question is whether other plausible stories or models can produce a similar U-shaped life-cycle pattern in the pricing of financial products. I will propose two such stories, both of which borrow elements from the literature on relationship lending. The first examines how age can affect the expected value of a bank-borrower relationship. The second looks at how a bank's ability to extract rents from a borrower may vary with the borrower's age. These models are not meant to be realistic or particularly sophisticated. They are just simple examples of how some of the empirical evidence in the paper could be explained with models of bank competition that do not rely on bounded rationality.

Banks value lending relationships. One reason may be that having a relationship with a customer makes it easier to sell additional products to that customer. Or, in a more complex model, it may be that relationships allow banks to gather valuable private information about the borrower. This can explain the widespread practice of offering introductory teaser rates on credit cards and other loans, ${ }^{2}$ and that of offering attractive terms to borrowers willing or likely to buy multiple products. For example, according to the president of one major bank, in Europe before the current crisis the margin on prime mortgages was so low that banks were losing money on them. However, selling those mortgages brought in new customers who would then buy wealth management services, trading services, and the like.

Relationships, however, are not forever. They can be broken by exogenous shocks, such as changes in the preferences or needs of the customer, or when the customer moves or dies. The longer the expected life of a relationship, the greater its value. The value of a relationship will also depend on the degree to which it allows the bank to extract rents from the customer. The higher the switching costs and informational barriers that prevent competing lenders from successfully poaching each other's customers, the more a relationship is worth.

2. See Petersen and Rajan (1995) for evidence of how bank market power affects introductory rates. 
Figure 1. A Model of the Bank-Customer Relationship over the Life Cycle

Percent
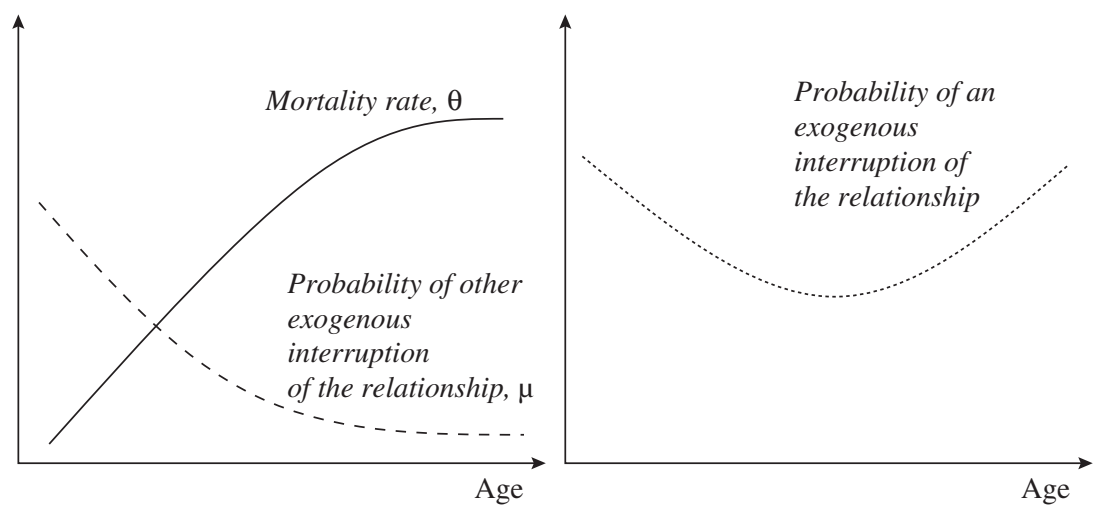

Source: Authorís model described in the text.

Consider now the following barebones model. Two banks compete on the interest rate to extend loans to customers of equal creditworthiness but different ages. Banks obtain profits from these loans but also benefit from establishing a relationship with the customer. Relationships, however, can be broken with probability $\theta$ by the death of the customer, or with probability $\mu$ by some other exogenous shock such as the customer moving to a different state. $\theta$ is obviously increasing with age. But it is reasonable to assume that $\mu$ is decreasing with age, since, for example, older people are less likely to change jobs (left-hand panel of figure 1). Then, normalizing the bank's cost of funds to 1 , the profit from extending a loan at a gross interest rate $r$ is

$$
\varphi r-1+\delta(1-\theta)(1-\mu) V
$$

where $\varphi$ is the probability that the borrower will repay the loan, $\delta$ is the discount factor, and $V$ is the value of the relationship. With Bertrand competition driving profits to zero, in equilibrium we have

$$
\hat{r}=\frac{1-\delta(1-\theta)(1-\mu) V}{\varphi},
$$

which, for a broad range of distribution functions for $\theta$ and $\mu$, delivers a U-shaped life-cycle pattern for interest rates consistent with the evidence 
in the paper (right-hand panel of figure 1). However, in this case the age-dependent pattern reflects changes in the probability of an exogenous interruption of the relationship rather than cognitive decline. If, in addition, one assumes that middle-aged clients are those most likely to be interested in multiple banking products (so that $V$ follows a hump-shaped pattern with respect to age), this pattern is reinforced further.

A model of bank competition under asymmetric information can deliver a similar pattern. Consider another simple framework where banks learn about their clients' creditworthiness over the course of a relationship. ${ }^{3}$ Further, assume that a portion $\lambda$ of these borrowers are captives of their bank in that they find it difficult to signal their credit quality to competing lenders. It follows that inside lenders will charge the monopoly interest rate, $R$, to the captive borrowers but will be forced to offer the competitive rate, $r$, to those borrowers that can signal their quality. The average rate observed on the market will then be a function of the proportion of captive borrowers, $r^{*}=\lambda R+(1-\lambda) r$. It is also reasonable to assume that the proportion of captive borrowers is a function of age: young borrowers with limited track records and credit histories, and older borrowers with few current transactions, may find it more difficult than middle-aged borrowers to signal their quality. Then, consistent with the evidence in the paper, the average interest rate charged to borrowers will follow a U-shaped pattern with respect to age.

These simple models show that a U-shaped pattern of interest rates with respect to age can be generated with models of bank competition, without resorting to unconventional assumptions. I now turn to the two most convincing pieces of empirical evidence in the paper: the eureka moments on credit card balance transfers and the rate-changing mistakes on home equity loan applications. For these, my task is more difficult.

Let me start with the eureka moments. A set of borrowers are offered the opportunity to transfer their current credit card balances to a new card charging a very low (teaser) interest rate on the transferred balance for a limited period. The catch is that new purchases on the new card face a high APR, and payments on the new card are credited first to the transferred (low APR) balance. In that case the optimal strategy is to take advantage of the low-interest-rate offer by transferring existing balances but to continue to use the old card for new purchases. And the evidence in the paper shows, after controlling for individual factors, that the per-

3. This is a common assumption in models of competition under asymmetric information. See, for example, Sharpe (1990) and Dell'Ariccia and Marquez (2004). 
centage of borrowers that actually follow this strategy has a hump-shaped pattern with respect to age. Put differently, a higher proportion of middleaged than of younger and older borrowers discover the optimal strategy and put it into practice.

The simple models described above cannot immediately explain this pattern of financial mistakes. Yet they are not necessarily irrelevant to the issue. Consider the following argument. The paper implicitly assumes that the interest rate charged on new purchases with the new card is higher than the rate paid on the old credit card. If this is true, the proposed strategy is indeed optimal. If not, things are more complicated, and it may be optimal for borrowers to use the new card for at least some purchases. But the authors' dataset lacks information on the interest rates borrowers were paying on their old cards. Consistent with the models above, it is not unreasonable to assume that middle-aged people on average pay lower rates on their existing credit cards and have greater access to low-interest-rate credit cards or other low-cost sources of funds generally. Then the eureka moment result could be explained in terms of a heterogeneity of optimal strategies rather than of cognitive abilities. In fact, without information about the rates paid on the old cards, the two explanations are observationally equivalent.

Now let me turn to the evidence on rate-changing mistakes. The authors find that the average interest rate paid by borrowers on home equity loans follows the by-now-familiar U-shaped pattern with respect to age. However, the pattern disappears for borrowers that provide a correct estimate of the value of their home. Put differently, conditional on borrowers applying for the "right" loan (one with the loan-to-value ratio appropriate for their home), the interest rate they are charged is roughly constant with respect to age. What drives the age pattern is the larger percentage of younger and older applicant borrowers who grossly underestimate the value of their home.

This is the strongest piece of evidence in support of the authors' hypothesis, and it is especially difficult to explain with an industrial organizationbased model. Of course, one could argue that some borrowers make more mistakes not because they are cognitively impaired or less experienced, but because they have fewer opportunities to learn. For instance, borrowers who interact more often with the banking system might receive multiple loan offers and consequently have a more accurate estimate of the value of their home. This group might consist disproportionately of middle-aged borrowers. Alternatively, it might be that loan officers are more willing to suggest the optimal strategy to their more valuable customers, who are again 
disproportionately those of middle age. But these assumptions are far from standard and represent a much more convoluted explanation of the evidence than the cognitive decline model.

Finally, I want to turn briefly to the policy implications of the paper. Obviously these depend on the mechanism one believes is at play. I believe the authors present convincing evidence that cognitive decline is at least partly responsible for the documented life-cycle pattern in financial performance. That said, the authors are rightly cautious when it comes to policy recommendations. In addition to the alternative possible explanations for the evidence (such as those discussed above), there is the question of how economically significant the identified age effects are. The paper reports relatively small economic damages associated with aging, which would not by themselves justify ad hoc regulatory intervention. However, as the authors argue, these costs may be the tip of the iceberg. Financial vulnerability in old age is a much broader issue, including exposure to outright fraud that can put one's entire life savings at risk.

Perhaps more important, several of the more paternalistic proposals in the paper can infringe on individual freedom. This raises two questions. The first is one of principle: Should society constrain an individual's right to control her own wealth just because she belongs to a group that is statistically more likely to make financial mistakes? What if similar results were found for groups identified by sex, or ethnicity, or education? The second question is a practical one: Several of the policies discussed in the paper would likely be difficult to implement, or politically infeasible, or both. After all, as Karen Pence documents in her discussion of this paper, the United States imposes very few restrictions on driving by senior citizens, even though the externalities are far more evident. That said, the evidence in the paper could be safely used to provide guidance for resource allocation in the context of consumer protection programs. For example, education and efforts against predatory lending could be targeted to more vulnerable areas and groups.

\section{REFERENCES FOR THE DELL'ARICCIA COMMENT}

Dell'Ariccia, Giovanni, and Robert Marquez. 2004. "Information and Bank Credit Allocation." Journal of Financial Economics 72, no. 1: 185-214.

Petersen, Mitchell A., and Raghuram G. Rajan. 1995. "The Effect of Credit Market Competition on Lending Relationships." Quarterly Journal of Economics 110, no. 2: 407-43.

Sharpe, Steven A. 1990. “Asymmetric Information, Bank Lending, and Implicit Contracts: A Stylized Model of Customer Relationships." Journal of Finance 45, no. 4: 1069-87. 


\section{COMMENT BY}

KAREN M. PENCE Older and younger individuals are more likely to pay higher prices for financial products than individuals in their middle years. Sumit Agarwal, John Driscoll, Xavier Gabaix, and David Laibson document this fact in several consumer finance markets, including markets for mortgages, credit cards, and auto loans. The age-related pattern holds after controlling for other features of the credit contracts and for borrowers' other demographic, financial, and risk characteristics, suggesting that older and younger individuals could have paid less than they did. I follow the authors in labeling this phenomenon a "mistake," although determining this with certainty would require knowledge of the full range of each borrower's options, which is lacking.

The authors assemble evidence from the medical, psychological, and economic literatures that suggests that older individuals make mistakes because of declining cognitive ability, whereas younger individuals appear to make mistakes because of inexperience. Although both groups are more prone than middle-aged individuals to make mistakes, the paper focuses primarily on the financial decisionmaking of older individuals.

The authors explore a range of possible regulatory responses, including doing nothing, requiring a financial "driver's license" to invest in nonstandard products, strengthening the fiduciary duties of financial salespeople, and requiring explicit regulatory approval of financial products. The authors decline to take a stand on which interventions, if any, are desirable.

The empirical work in this paper is clear and convincing, and the authors place their findings in a broad and rich context. However, many of the possible regulatory responses may prove politically unpalatable: the political system seems reluctant to impose restrictions on the behavior of older individuals, even when such restrictions may be warranted. I describe below two situations in which both younger and older individuals are more likely to make mistakes, yet regulations are considerably more comprehensive for younger than for older individuals.

DRIVING. Teenage drivers and older drivers are both more likely than other drivers to be involved in car crashes (Liu, Utter, and Chen 2007). As drivers age, the advantage of their greater experience is eventually outweighed by physical factors such as degradation of reflexes, vision, and hearing, and decreases in strength, mobility, and ability to process information (Islam and Mannering 2006). In addition, because of their relative frailty, older drivers are more likely to be injured or killed in a crash: drivers 65 or older have almost three times the odds of drivers 24 or younger of being seriously injured in an auto accident (Liu and others 2007). 
Figure 1. Automobile Fatalities by Driver Age, 1999-2003

Per billion miles driven

\section{Driver fatalities}

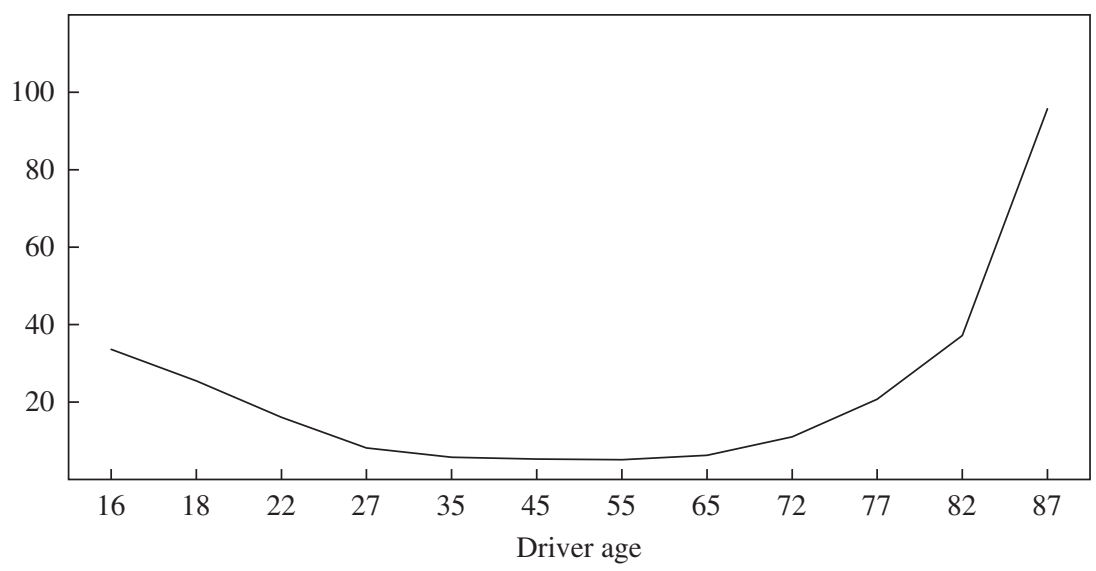

Nonmotorist fatalities ${ }^{\mathrm{a}}$

Per billion miles driven

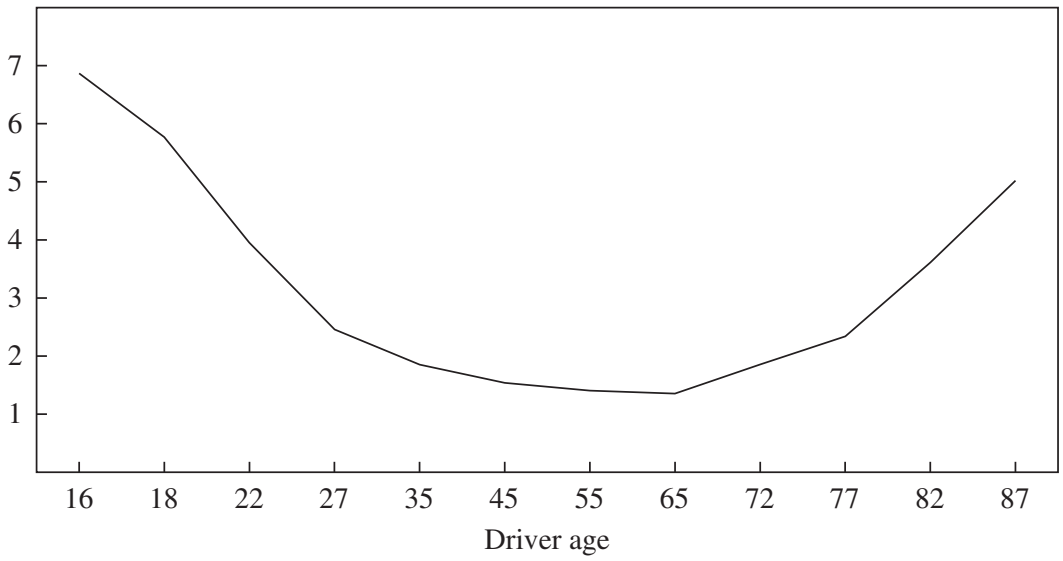

Source: Author's calculations from data in Tefft (2008).

a. Persons killed in auto accidents who were not riding in an automobile.

The top panel of figure 1 shows driver deaths by age, scaled by billions of miles driven by members of the age group. The age-related pattern is dramatic: on average, 34 drivers aged 16 and 17, 5 drivers in their forties, and 96 drivers age 85 or older were killed per billion miles driven over the 1999-2003 period. 
The bottom panel of the figure shows nonmotorist (such as pedestrian) deaths by driver age, again scaled by billions of miles driven. This figure isolates the age-related pattern due to driver error rather than the relative frailty of older drivers. The pattern is still apparent but is less dramatic: on average 7 nonmotorists were killed by drivers aged 16 and 17, about 2 were killed by drivers in their forties, and 5 were killed by drivers aged 85 or older.

Figure 1 suggests that the argument for age-based regulation of driving is compelling. And indeed, states are highly involved in regulating teenage driving. Almost all have adopted a form of "graduated licensing," which includes some combination of a learner's period during which parents may have to certify a certain amount of supervised driving, and an intermediate period during which night driving and teenage passengers may be prohibited or limited (Insurance Institute for Highway Safety 2009a).

States regulate older drivers, however, with a substantially lighter touch. Twenty-four states place no restrictions on older drivers, and in Tennessee, licenses issued to drivers 65 years or older never expire (Insurance Institute for Highway Safety 2009b). Four states and the District of Columbia forbid licensing administrators to treat people differently solely on the basis of advanced age, and only New Hampshire and Illinois require road tests for older drivers.

CREDIT CARDS. As the paper documents, both younger and older individuals appear to pay higher credit card interest rates and fees than those in between. Policymakers and consumer groups have also raised concerns about the use of credit cards by students and the elderly, but only the concerns about the former have been translated into law. ${ }^{1}$

Legislation enacted in 2009 imposes broad changes on the credit card industry. The Credit Card Accountability, Responsibility, and Disclosure Act has no provisions specific to the elderly, but it does place significant restrictions on the access of young borrowers to credit cards. An applicant under the age of 21 may open a credit card account only with a co-signer age 21 or older, unless the applicant submits evidence of independent means to repay. Issuers are not allowed to send unsolicited prescreened credit offers to individuals under the age of 21 , and they may not increase the credit lines of accounts with a co-signer without the co-signer's permission.

POLICY IMPLICATIONS. The above two examples suggest that policymakers and the public are comfortable protecting young individuals from their

1. See General Accounting Office (2001) for an overview of the issues surrounding students and credit cards, and García (2007) for an example of concern about older households' credit card debt. 
inexperience, but are less comfortable protecting older individuals from their declining mental or physical abilities. Thus, popular support may be low for many of the regulatory responses outlined in this paper.

Perhaps support would be higher if the costs of the financial mistakes that older people make were more apparent. This paper cannot make that case, because the costs of the mistakes the authors identify are not particularly large. For example, they show that older borrowers pay perhaps $\$ 5$ to $\$ 20$ more in credit card rates and fees than middle-aged borrowers. In the most costly example of the 10 that the authors document, older borrowers may pay around $\$ 250$ more on their home equity lines annually than middle-aged borrowers.

In contrast, mistakes that older households make in managing and investing their retirement savings may have significant quality-of-life consequences. As the authors note, more research is needed about the consequences of these and other mistakes for policymakers to formulate appropriate regulatory responses. However, research alone may not be enough. For example, the costs of driving by the elderly are large and well measured, but the policy response does not seem commensurate.

\section{REFERENCES FOR THE PENCE COMMENT}

García, José A. 2007. "Borrowing to Make Ends Meet: The Rapid Growth of Credit Card Debt in America." New York: Dēmos. www.demos.org/pubs/ stillborrowing.pdf.

General Accounting Office. 2001. "Consumer Finance: College Students and Credit Cards." Washington.

Insurance Institute for Highway Safety. 2009a. "U.S. Licensing Systems for Young Drivers." Arlington, VA. www.iihs.org/laws/pdf/us_licensing_systems.pdf.

_ 2009b. "Licensing Renewal Provisions for Older Drivers." www.iihs.org/ laws/OlderDrivers.aspx.

Islam, Samantha, and Fred Mannering. 2006. "Driver Aging and Its Effect on Male and Female Single-Vehicle Accident Injuries: Some Additional Evidence." Journal of Safety Research 37, no. 3: 267-76.

Liu, Cejun, Dennis Utter, and Chou-Lin Chen. 2007. "Characteristics of Crash Injuries among Young, Middle-Aged, and Older Drivers." National Highway Traffic Safety Administration Technical Report DOT HS 810 857. Washington.

Tefft, Brian C. 2008. "Risks Older Drivers Pose to Themselves and to Other Road Users." Journal of Safety Research 39, no. 6: 577-82.

GENERAL DISCUSSION Linda Goldberg said she accepted the idea that experience rises with age while cognitive abilities decline, and she found the evidence for a U-shape of costs persuasive. She was not yet 
convinced, however, that the former explains the latter. Issues also remain regarding the self-selection of borrowers: are older borrowers different from the rest of the older population, given that the general expectation, from a life-cycle perspective, is for borrowers to be younger? She also observed that with product bundling, customers purchasing the most sophisticated or broadest set of products might be offered lower interest rates. Also, other issues relating to supply of credit need to be controlled for before deciding whether regulation or some other policy is appropriate.

Robert Hall conceded that there are quite noticeable age effects in financial performance, but he noted that the correlation is very low: one can easily think of extreme outliers, like Warren Buffett. The paper's results might be more powerful if expressed in terms of a relationship to some aptitude score rather than to age. With respect to mortgages, the presumption is that the amount a person pays depends on the cost of serving that person as well as on the person's skill in choosing financial products. For example, the U-shaped relationship between mortgage expense and age might reflect higher costs of originating mortgages for the young and the old.

Hall also noted that mandatory mortgage counseling appears to have been quite successful at improving consumers' choice of a mortgage. Apart from that, however, Hall shared the general frustration with the lack of good policy options, particularly regarding labeling and disclosure. The only kind of labeling that might provide a useful model, he thought, is nutrition labeling, for which some excellent research was done to determine the absolute minimum amount of information necessary and how to present it. The so-called Schumer box now required of credit card issuers should look like the nutrition label on the side of a box of cereal, but instead it is lengthy and difficult to read. Hall concluded that there is still a long way to go on disclosure, but he doubted that even better disclosure would do much to resolve the problem.

Alan Blinder observed that the authors were very agnostic about remedies, almost to the point of suggesting that nothing will work, and he urged a little less agnosticism. He suggested a distinction between policies that rely on engaging the brain through improving financial literacy or greater disclosure, and policies that are more paternalistic, such as good default options, nudges, and fiduciary standards, which he thought the paper too easily dismissed. Blinder disputed the contention that stockbrokers are obligated only to avoid misrepresentation. There is a suitability standard for brokers, which prohibits them from pressuring 
anyone, let alone the elderly, into inappropriate investments. He agreed, however, that there is a lot of room to raise fiduciary standards and prevent abuse.

Christopher House agreed with Goldberg that differences in performance across age per se do not seem to be the key, and he suggested that it would be better to think in terms of the level of cognitive ability. He further observed that although cognitive ability does decline with age, there are often other people present who have the interests of an aging household in mind. For example, just as parents encourage their children to drive safely, save their money, and choose a good subject for their major, so the grown children of older people often give them advice about finances and other important decisions. The presence of these familial supports complicates the situation and argues for caution in devising a regulatory structure that might interfere with these supports.

Benjamin Friedman also urged a clearer distinction between nudges and disclosure, especially if the authors generally approve of the former and are skeptical of the latter. The discussion of nudges in the paper reminded Friedman that in the recent book Nudge by Cass Sunstein and Richard Thaler, many of the proposed nudges amounted to no more than disclosure. Friedman was also skeptical of the idea that small-scale trials would be very informative. A mantra of the financial industry is that securities are not bought; they are sold. In a small-scale trial, however, firms lack the incentive to develop the well-financed marketing effort to sell securities or other financial products to people who otherwise would not buy them. Thus, if a small-scale trial suggests that a given intervention leads only a few people to buy an inappropriate product, that sheds little light on what will happen when the industry is unleashed on a large population of prospective buyers and thus has an incentive to sell aggressively.

Christopher Sims argued that not enough is known about the process by which younger people start taking over decisionmaking for their elderly relatives, and especially what happens to people who lack educated, financially well off, or even living children to take care of them. The issue goes well beyond finance. When a person gets Alzheimer's, for example, eventually not only financial decisions become difficult, but also what to eat in the morning, what to wear, and how to maintain one's home. Adding to the problem is that Alzheimer's patients often lose all perspective on their abilities. A further problem is that some charities seem to increase the frequency of their requests for contributions addressed to older people, because they know that elderly people, especially those with Alzheimer's, 
often forget how much they have given in the recent past. For some relatively wealthy households, the financial impact of this practice may be as important as the credit card issues discussed in the paper.

Christopher Carroll framed his comment by quoting the philosopher Isaiah Berlin, who said that one of the most important individual rights is the right to make your own mistakes. Any rigorous investigation into optimal financial regulation has to take into account the fact that people often learn valuable lessons from their mistakes. Indeed, this could be one reason why the experience profile is so sharply upward sloping. Berlin's point is less persuasive, however, with respect to decisions that one cannot easily revisit, such as lifetime saving decisions. This suggests that the need for regulation of financial products should depend in part on whether the transaction is likely to be a one-time event, or one that is likely to be repeated with the benefit of learning.

Justin Wolfers thought the paper should do more to highlight not just the types of mistakes being made and their relationship to the life cycle, but also the consequences of those mistakes. He observed further that the economics profession at the moment is thinking a lot about methodology, and in particular about what contributes to making results "robust." The present paper gathers a wealth of evidence across many different decisions and different datasets, which adds robustness in a different sense than adding another control variable. It is a wonderful case study in that respect. The paper also succeeds in identifying examples of behavior that are unambiguously suboptimal. For example, when using a credit card with a teaser rate to which one has transferred a balance, it is absolutely clear that one should not use that credit card for purchases. There is no possible story where such a transaction represents a rational decision.

Ricardo Reis suggested two explanations for why there are more legal restrictions on the young than on the old. First, the old vote and the young do not. Second, when a teenager has a horizon of 60 or 70 years of driving ahead but is prohibited from driving for the first 3 , the cost does not seem as high as when a 65 -year-old with 15 years of expected life ahead is prevented from driving. This may be what leads older people to resist restrictions on their actions more than the young. Reis also stressed the distinction between fiduciary duties and regulatory authority. The authors drew a parallel between financial products and medicines, but Reis believed the right model for financial products was much closer to prescription drugs than to over-the-counter drugs. Prescription drugs must be approved for sale by the FDA, but in addition they have to be recommended by a doctor for each patient individually and prescribed in the right doses. The 
doctor's approval is as important as the FDA's, if not more important. Similarly, any governmental authority approving a financial product will always have to rely ultimately on the broker or seller bearing some fiduciary responsibilities.

Reis added that there is a separate question about fiduciary responsibility in the health field, namely, whether doctors are making poor financial decisions for their patients and for taxpayers. Doctors are trained for 15 years and indoctrinated into thinking about their patients first; they take an oath to do so and can be not only disbarred but jailed for a wrong medical decision. Yet there is no comparable sanction for their decisions that go against the financial interest of a patient, not to mention that of the taxpayer.

Alan Auerbach disagreed with Reis's comparison, arguing that there is a big difference between making a decision in the interest of a patient and making a decision in the interest of the taxpayer. Although this setup is one reason for the current problems in the health care system, it can be fully rational and in the interest of the patient for the doctor to make a decision against the taxpayer's interest. Justin Wolfers added, with respect to the FDA analogy, that off-label drug use is enormous. Medicines may be approved for one use, yet most of the sales of that drug may end up being used for something else. Much the same thing could well happen under stronger financial regulation.

Chang-Tai Hsieh wondered whether the phenomenon that the paper identified is big or small. He suggested two possible dimensions for gauging its importance. First, is the choice of a financial product among the most important decisions a person makes, or merely one of many important decisions? People might, for example, be making serious mistakes in other areas, such as schooling for their children, or what kind of home to buy. The potential welfare consequences from these mistakes could be even larger than those from poor financial decisions. Second, is age really the most important source of variation in cognitive ability? Suppose one could administer a test that accurately measures that variation, and in particular how much of the variance can be explained by age. The latter result, Hsieh predicted, is likely to be small; other considerations, such as differences in income, might well be more important.

Timothy Besley suggested looking not just at mean differences between age groups, but also at the variance. One reason why there is less resistance to intervening with the young could be that competence at financial decisionmaking is fairly tightly distributed within some age groups: most young people are more or less equally bad at making such decisions, but the distribution seems to fan out as people get older. This would have dif- 
ferent redistributive implications at different points in the age distribution. Besley also observed that what matters is the margin and not the average: the paper's results support doing something about both the old and the young, but they do not yet imply that the marginal return to intervening with those groups is highest. Besley argued further that one should not give up on the role of tort law in resolving some of these issues. To be sure, not all regulatory issues can be resolved in court ex post, but fines and other standard tort mechanisms do have their place.

Robert Hall responded by suggesting that in the United States the tort system effectively does not apply to financial products at all. Most financial products sold in this country require that the buyer sign a mandatory arbitration agreement. This protects the providers of financial products from liability but amounts, in Hall's view, to the forfeiture of tort rights by the purchaser. Christopher Carroll countered that although at present there is no effective role for the court system in financial matters, that does not mean that it is not a useful thing to contemplate. In fact, he noted, one large credit card issuer recently claimed to have moved away from the arbitration requirement.

Karen Dynan seconded Hsieh's comment on the importance of measuring the costs of people's financial mistakes. Regulation is not costless; the question for policy is whether the losses associated with it are worth bearing. Dynan said she was sympathetic to the view that cognitive abilities decline with age, but she offered an alternative possible explanation for the paper's results: older people might put less time and effort into financial decisions because of shifting priorities. Many people toward the end of life say they wish they had spent less time working. They might say the same thing about trying to figure out exactly the right interest rate on a credit card. It would be interesting to see whether older people do try as hard as younger ones when making financial decisions.

William Nordhaus commented that the paper reminded him of certain issues in the energy area, where there are also well-documented inefficiencies, the reasons for which are poorly understood. He saw three similarities across the two sets of issues. First, the inefficiencies are stubborn and do not disappear over time. For well over three decades now, the United States has had various policies in place to improve energy efficiency, yet first-price bias in the purchasing of automobiles and the overdiscounting of fuel use appear almost as prevalent today as when they were first investigated in the 1970s. No one should underestimate how difficult it will be to change this kind of behavior. Second, careful labeling of energy-consuming goods like appliances appears to have made some difference, but it is 
necessary not just to do the calculations, but also to undertake a fair number of behavioral studies. Third, one should never underestimate Congress's ability to devise very poor, heavily interventionist policies. When designing new financial regulations, policymakers would do well to remember that the SUV was invented basically to get around energy regulations and fuel economy standards. The ability and the incentives of financial engineers to devise the financial equivalent of SUVs should not be taken lightly.

George Perry wondered whether, instead of allowing certain products to be sold but forbidding certain groups of people to buy them, the solution might be to place restrictions on what is available for anyone to buy. This would raise obvious issues of freedom of choice, but on the other hand no one disagrees that the Bernie Madoffs of the world should be put in jail and should not be allowed to peddle fraudulent goods. Perry noted that banks continue to charge outrageous fees on debit card overdrafts, and on card accounts generally, and although the amounts are small compared with the loss of one's home, they are nonetheless considerable. Perry could think of no other area where regulation permits what is universally agreed to be an unfair price, yet companies remain free to set these unconscionable fees. 
